\title{
The IAEA Coordinated Research Program on HTGR Uncertainty Analysis: Phase I Status and Ex. I-1 Prismatic Reference Results
}

\author{
Friederike Bostelmann $^{1 \mathrm{a}}$, Gerhard Strydom $^{\mathrm{a}^{*}}$, Frederik Reitsma $^{\mathrm{b}}, \operatorname{Kostadin} \operatorname{Ivanov}^{\mathrm{c}}$ \\ ${ }^{a}$ Nuclear Science and Engineering Division, Idaho National Laboratory (INL), 2525 N. Fremont Ave., Idaho \\ Falls, ID 83415, U.S.A. gerhard.strydom@inl.gov, friederike.bostelmann@grs.de \\ ${ }^{\mathrm{b}}$ Division of Nuclear Power, International Atomic Energy Agency (IAEA), Vienna International Centre, PO Box \\ 100, A-1400 Vienna, Austria. F.Reitsma@iaea.org \\ ${ }^{\mathrm{c}}$ Nuclear Engineering Department, North Carolina State University (NCSU), 2500 Stinson Drive, Raleigh, NC \\ 27695, U.S.A. knivanov@ncsu.edu \\ * Corresponding author
}

\begin{abstract}
The quantification of uncertainties in design and safety analysis of reactors is today not only broadly accepted, but in many cases became the preferred way to replace traditional conservative analysis for safety and licensing analysis. The use of a more fundamental methodology is also consistent with the reliable high fidelity physics models and robust, efficient, and accurate codes available today. To facilitate uncertainty analysis applications a comprehensive approach and methodology must be developed and applied, in contrast to the historical approach where sensitivity analysis were performed and uncertainties then determined by a simplified statistical combination of a few important input parameters. New methodologies are currently under development in the OECD/NEA Light Water Reactor (LWR) Uncertainty Analysis in Best-Estimate Modelling (UAM) benchmark activity. High Temperature Gas-cooled Reactor (HTGR) designs require specific treatment of the double heterogeneous fuel design and large graphite quantities at high temperatures. The IAEA has therefore launched a Coordinated Research Project (CRP) on HTGR Uncertainty Analysis in Modelling (UAM) in 2013 to study uncertainty propagation specifically in the HTGR analysis chain.
\end{abstract}

Two benchmark problems are defined, with the prismatic design represented by the General Atomics (GA) MHTGR-350 and a 250 MW modular pebble bed design similar to the Chinese HTR-PM. Work has started on the first phase and the current CRP status is reported in the paper. A comparison of the Serpent and SCALE/KENO-VI reference Monte Carlo results for Ex. I-1 of the MHTGR-350 design is also included. It was observed that the SCALE/KENO-VI Continuous Energy (CE) $k_{\infty}$ values were 395 pcm (Ex. I-1a) to 803 pcm (Ex. $I-1 b)$ higher than the respective Serpent lattice calculations, and that within the set of the SCALE results, the KENO-VI 238 Multi-Group (MG) $k_{\infty}$ values were up to 800 pcm lower than the KENO-VI CE values. The use of the latest ENDF-B-VII.1 cross section library in Serpent lead to $\sim 180$ pcm lower $k_{\infty}$ values compared to the older ENDF-B-VII.O dataset, caused by the modified graphite neutron capture cross section. The fourth beta release of SCALE 6.2 likewise produced lower CE $k_{\infty}$ values when compared to SCALE 6.1, and the improved performance of the new 252-group library available in SCALE 6.2 is especially noteworthy. A SCALE/TSUNAMI uncertainty analysis of the Hot Full Power variant for Ex. I-la furthermore concluded that the ${ }^{238} U(n, \gamma)$ (capture) and ${ }^{235} U(\overline{\boldsymbol{v}})$ cross-section covariance matrices contributed the most to the total kळ uncertainty of $0.58 \%$.

Keywords: HTGR, uncertainty, prismatic, pebble bed

\footnotetext{
${ }^{1}$ Current Affiliation: Gesellschaft für Anlagen- und Reaktorsicherheit (GRS) gGmbH, Germany.
} 


\section{INTRODUCTION}

The continued development of High Temperature Gas Cooled Reactors (HTGRs) requires verification of HTGR design and safety features with reliable high fidelity physics models and robust, efficient, and accurate codes. One way to address the uncertainties in the HTGR analysis tools is to assess the sensitivity of critical parameters, such as the maximum fuel temperature during loss of coolant accidents, to a few important input uncertainties. The input parameters were identified by engineering judgement in the past but are today typically based on a Phenomena Identification Ranking Table (PIRT) process. The input parameters can also be derived from sensitivity studies and are then varied in the analysis to find a spread in the parameter of importance (Strydom, 2004). However, there is often no easy way to compensate for these uncertainties. In engineering system design, a common approach for addressing performance uncertainties is to add compensating margins to the system, but with passive properties credited it is not so clear how to apply it in the case of modular HTGR heat removal path (Lommers et al., 2014). Other more sophisticated uncertainty modelling approaches, including Monte Carlo analysis, have also been proposed and applied (Janse van Rensburg and Sage, 2006).

Ideally one wishes to apply a more fundamental approach to determine the predictive capability and accuracies of coupled neutronics/thermal-hydraulics and depletion simulations used for reactor design and safety assessment (Hao, 2012). Today there is a broader acceptance of the use of uncertainty analysis even in safety studies and it has been accepted by regulators in some cases to replace the traditional conservative analysis. Therefore some safety analysis calculations may use a mixture of these approaches for different parameters depending on the particular requirements of the analysis problem involved. Sensitivity analysis can for example be used to provide information as part of an uncertainty analysis to determine best estimate plus uncertainty results to the required confidence level (National Nuclear Regulator, 2006).

In the case of LWRs the Nuclear Regulatory Commission (NRC) amended 10 CFR 50.46 (U.S. NRC, 2014) to allow best-estimate (plus uncertainties) calculations of emergency core cooling system performance. The Nuclear Energy Agency (NEA) of the Organization for Economic Co-operation and Development (OECD) also established an Expert Group on "Uncertainty Analysis in Modelling" which finally led to the definition of the "Benchmark for Uncertainty Analysis in Modelling (UAM) for Design, Operation and Safety Analysis of LWRs" (Ivanov, et al., 2013). In order to address uncertainty propagation in analysis and methods in the HTGR community, the IAEA initiated a Coordinated Research Project (CRP) on the HTGR Uncertainty Analysis in Modelling (UAM) that officially started in 2013 (Tyobeka, 2011). Although this project focuses specifically on the peculiarities of HTGR designs and its simulation requirements, many lessons can be learned from the Light Water Reactor (LWR) community and the significant progress already made towards a consistent uncertainty analysis methodology. The CRP on HTGR UAM will follow as far as possible the on-going OECD/NEA LWR UAM benchmark activity.

In order to benefit from recent advances in modelling and simulation and the availability of new covariance data (nuclear data uncertainties), extensive sensitivity and uncertainty studies are needed to quantify the impact of different uncertainty sources on HTGR design and safety parameters. Only a parallel effort in advanced simulation and in nuclear data improvement will be able to provide designers with more robust and well validated calculation tools to meet design target accuracies. These studies can also be used in a convincing and effective manner to perform design optimization and to assess safety features and design margins, but only if the uncertainty information is of the highest quality, reliability and science-based.

\section{CRP ON HTGR UAM OVERVIEW}

The proposed technical approach is to establish and utilize a benchmark for uncertainty analysis in bestestimate coupled HTGR modelling and analysis, using as a basis a series of well-defined problems with complete sets of input specifications and as far as possible reference experimental data. The principal idea is to subdivide the coupled system calculation into several steps, each of which can contribute to the total uncertainty and to identify input, output, and assumptions for each step. The resulting uncertainty in each step will be calculated by taking into account all sources of uncertainties including propagating the related uncertainties from previous steps. The four phases are as follows: 
- Phase I (Local Standalone Modelling)

- Phase II (Global Standalone Modelling)

- Phase III (Design Calculations)

- $\quad$ Phase IV (Safety Calculations)

Two main HTGR types have been selected based on previous benchmark experiences and available data: a 250MWth pebble bed design based on the HTR-Module (Reutler and Lohnert, 1984), and a 350MWth prismatic design based on the Modular High Temperature Gas Reactor (MHTGR) (Epiney, et al., 2012). A detailed description of the two reactor designs, detailed background information and the methodology to be followed can be found in Reitsma (2012).

\subsection{Phase I}

The benchmark specification for Phase I requires the modelling of localized effects, and is divided into the exercises shown here.

\section{Exercise I-1: "Local Neutronics"}

This exercise is focused on the derivation of the multi-group microscopic cross-section libraries. Its objective is to address the uncertainties due to the basic nuclear data as well as the impact of processing the nuclear and covariance data, selection of multi-group structure, and double heterogeneity or self-shielding treatment. The intention is to propagate the uncertainties in evaluated Nuclear Data Libraries (NDL) (i.e. microscopic pointwise cross sections) into multi-group microscopic cross-sections for use in lattice calculations. Exercises I-1a and $\mathrm{I}-1 \mathrm{~b}$ are defined to capture the local neutronics effects.

Exercise I-1a/b-Cell Physics: Derivation of the multi-group microscopic cross-section libraries.

The single pebble unit cell, shown in Fig. 1, represents a pebble with a given burnup and with numberdensities provided for the main actinides and fission products. The reflective boundary condition implies that it is surrounded by the same fuel type. The unit cell for the MHTGR prismatic design is likewise defined, as shown in Fig. 2. Both specifications include number density and geometry data for the (xenon-free) Cold Zero Power (CZP) and Hot Full Power (HFP) conditions to study the effect of an increase in temperature. For the CZP and HFP conditions, all material temperatures are set at $293 \mathrm{~K}$ and $1200 \mathrm{~K}$, respectively. The homogeneous (TriStructural Isotropic (TRISO) kernel and compact matrix material volume-averaged) version of the specification is designated as Ex. I-1a, while Ex. I-1b requires the explicit modelling of the TRISO fuel kernels.

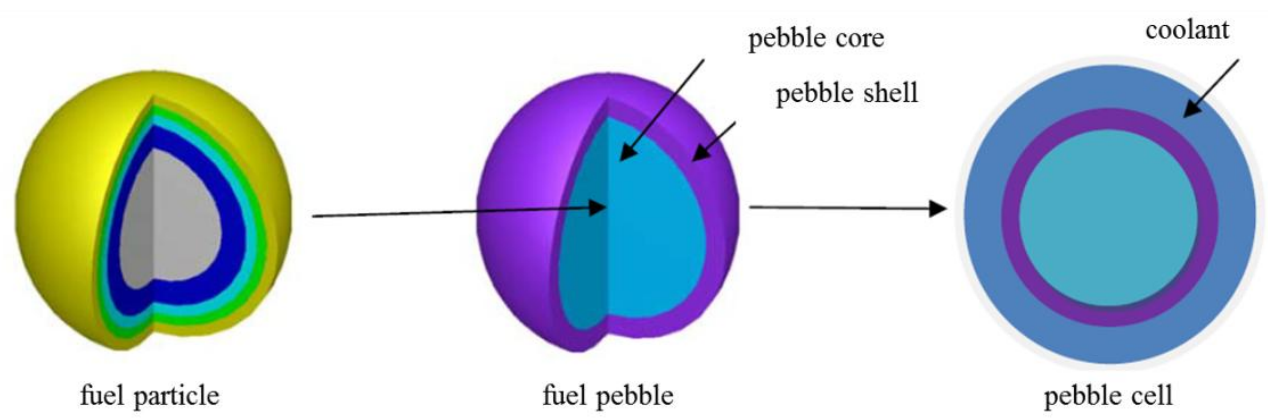

Fig. 1: Single pebble unit cell for Ex.I-1a (homogeneous pebble). 


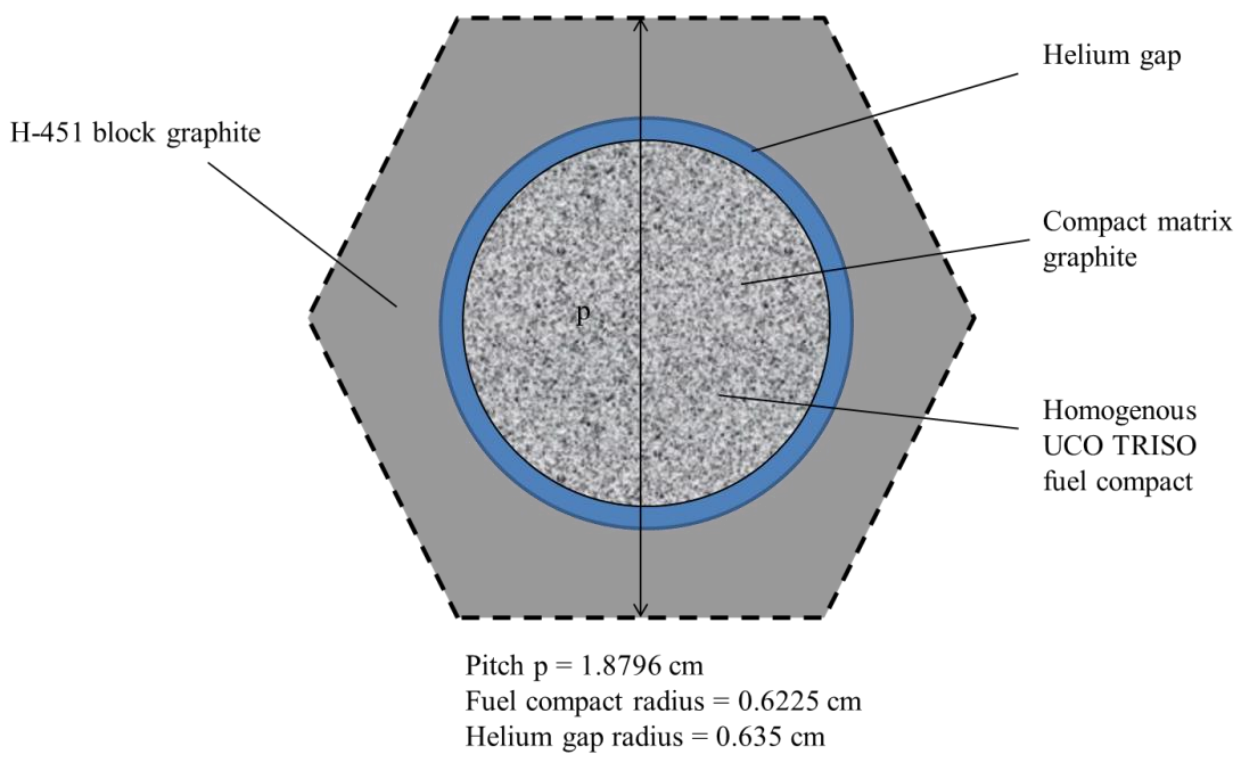

Fig. 2: Single MHTGR fuel compact unit cell for Ex. I-1a (homogeneous).

\section{Exercise I-2 - Lattice Physics: Derivation of the few-group macroscopic cross-section libraries}

In this case the correct environment of the pebble fuel needs to be taken into account in a "lattice physics" model. The target is to obtain few group parameters, variance / co-variance matrix for all homogenized crosssections including diffusion coefficients, Assembly Discontinuity Factors (ADFs), where applicable, and kinetic parameters for use in typical core solvers. One important issue in this exercise is the definition of a lattice. For the pebble reactor design the following considerations will be taken into account:

- $\quad$ one dimensional (1D) core calculation

- $\quad$ single pebble with different leakage conditions

- $\quad$ multiple pebbles (mixture of different compositions / burnup)

The 1D cut (slab or cylindrical) through the core is typically modelled of infinite height (random packing) with the reflectors modelled in a mini-core as shown in Fig. 3. The two alternative models are much simpler but rely on the definition of the correct isotopic mixtures and boundary conditions to try and represent the neutron spectrum in the core correctly. These are shown in Fig. 4. 


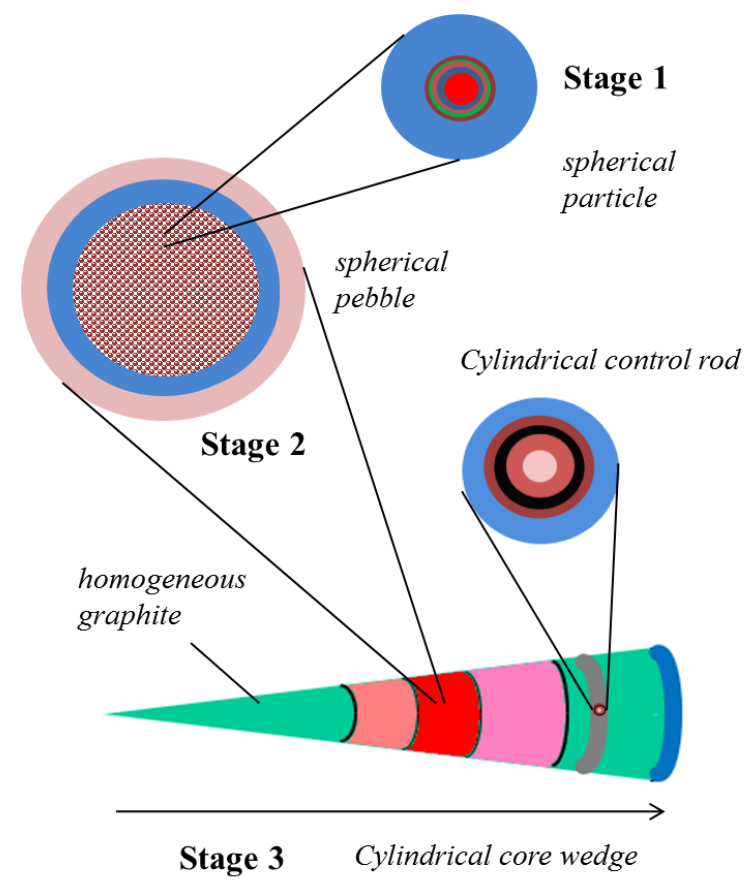

Fig. 3: Mini-core one-dimensional lattice cell for Ex. I-2.
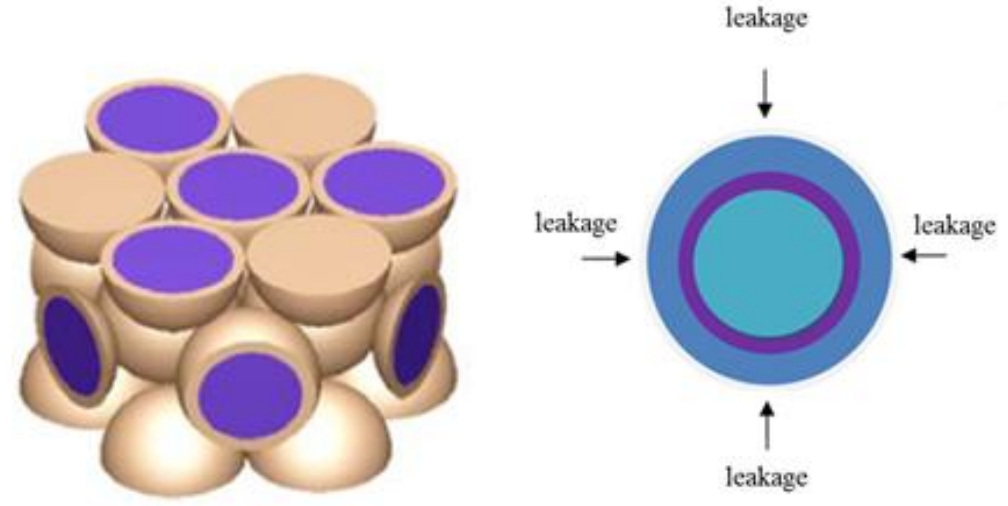

Fig. 4: Alternative lattice cell definitions for Ex.I-2.

For the prismatic lattice physics calculation, the geometry and number density data for a single MHTGR-350 hexagonal fuel block (shown in Fig. 5) is provided. A second variation of this problem adds the spectral effects of neighbouring blocks, as shown in the "supercell" in Fig. 6. 


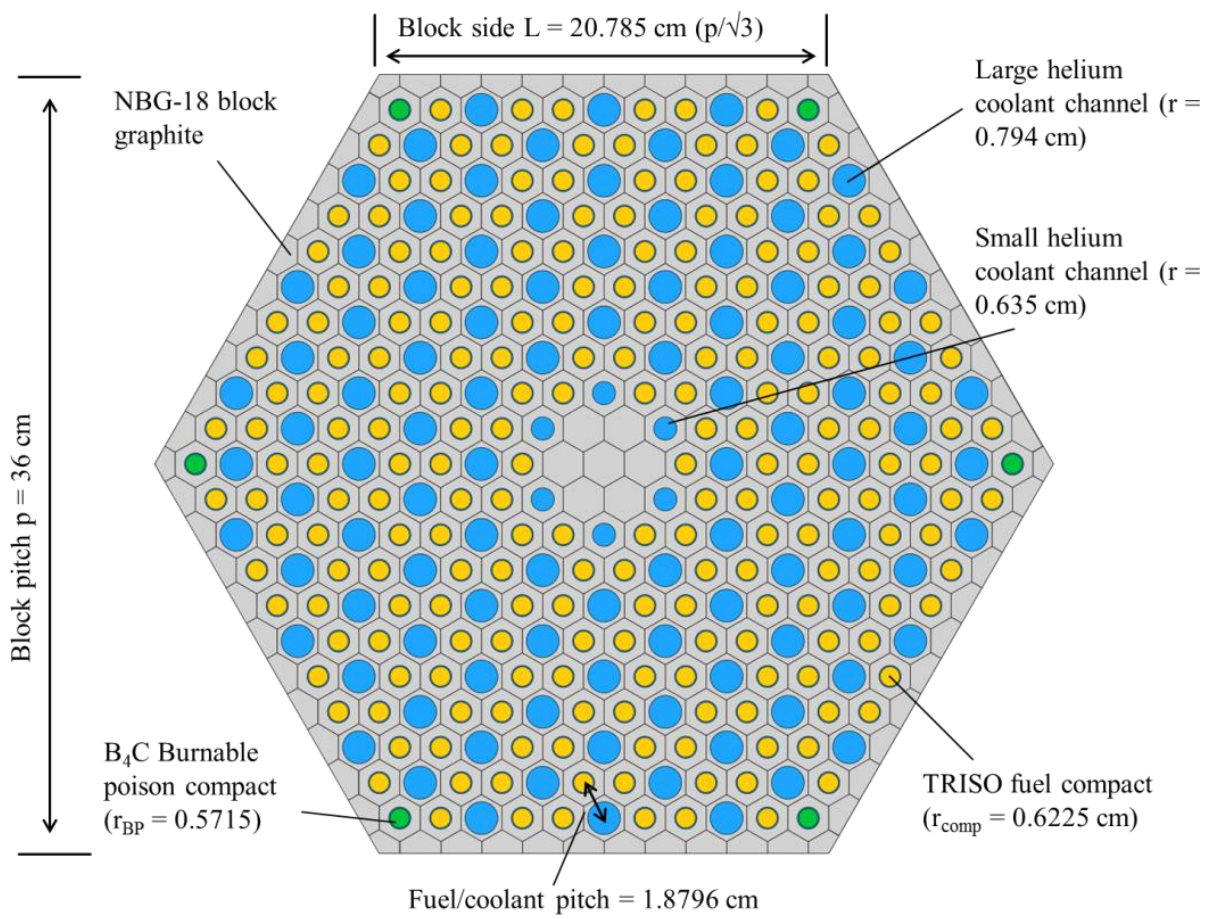

Fig. 5: MHTGR-350 lattice cell for Ex. I-2a (fresh single block).

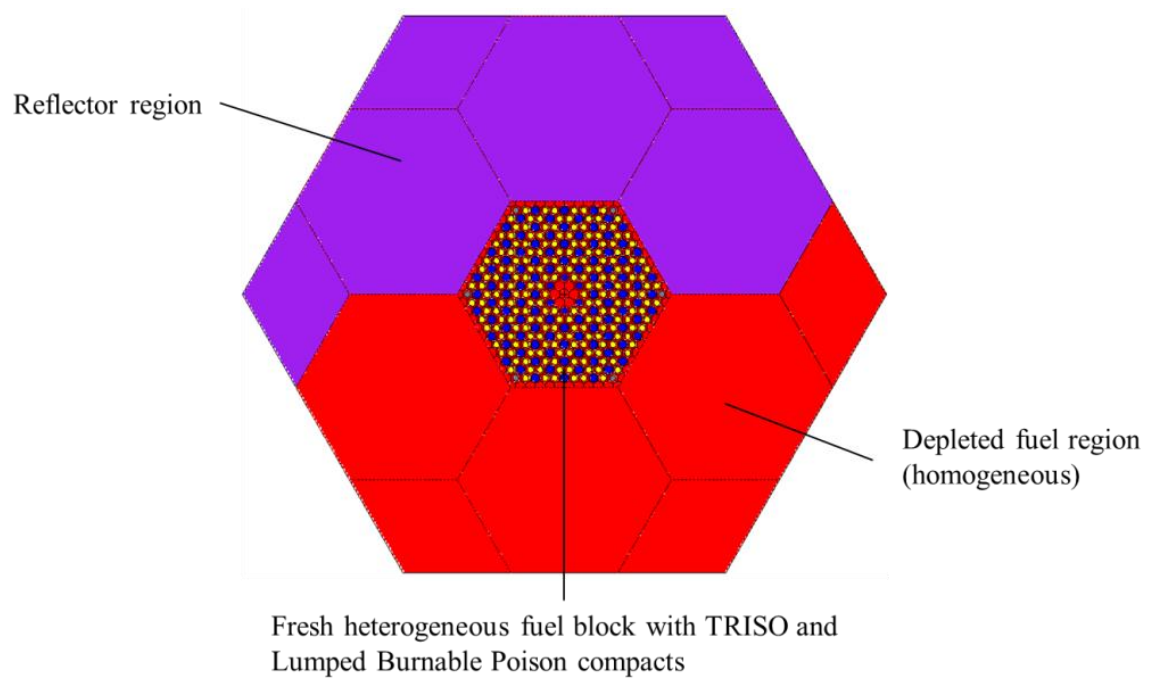

Fig. 6: Graphical Representation of Ex.I-2c Super-Cell.

The reference (or nominal/best estimate) results for Ex. I-1a and I-1b of the prismatic reactor design are presented in Section 3 (SCALE/KENO-VI and Serpent), and the corresponding SCALE/TSUNAMI uncertainty assessment results in Section 4. The two remaining exercises of Phase I consist of stand-alone steady-state (Ex. I-3a/b) and transient (Ex. I-4a/b) thermal hydraulics cell calculations (Reitsma, et al., 2012). The reference Computational Fluid Dynamics (CFD) results for the MHTGR-350 cell calculations were reported by Yoon and Strydom (2014).

\subsection{Phases II-IV}


The following cases are currently included in the benchmark specification for Phases II-IV (more detail can be found in Reitsma, et al., (2012):

\section{Phase II: Global Standalone Modelling}

- $\quad$ Exercise II-1a: Core physics: Criticality stand-alone neutronics.

- $\quad$ Exercise II-1b: Core physics: Stand-alone kinetics without feedback.

- Exercise II-2a/b: Stand-alone thermal-hydraulics focused on core thermal-hydraulic modelling (normal operation / Depressurized Loss of Forced Cooling transient).

\section{Phase III: Design Calculations}

- $\quad$ Exercise III-1: Coupled neutronics and thermal hydraulic steady-state.

- $\quad$ Exercise III-2: Coupled depletion and neutronics.

\section{Phase IV: Safety Calculations}

- $\quad$ Exercise IV-1: Coupled core transient.

- $\quad$ Exercise IV-2: Coupled system transient.

The initial progress has been slower than initially planned mostly due to the time and effort required to establish the tools and methodology. Some progress has been made by some institutions to develop these while others are dependent on the release of software that has uncertainty evaluation capabilities for double heterogeneity HTGR fuel. The second official Research Coordinated Meeting (RCM) was held in December 2014 where the first results from Idaho National Laboratory were presented and discussed. Other participating member states and institutions have also presented their preliminary results and these are in general agreement but will require more detailed study and comparison. In future no major delays are expected in the progress of especially the neutronic cases where the methodology and tools are now better understood.

The initial development of the two benchmark cases definitions were focussed on the complete core and system design. Although this is helpful to see the total scope of the work and provide valuable design specification for later phases and cases, it also delayed the release of the final specifications since the details of the later phases are not yet known. It was thus decided that specifications will be finalised per phase.

The cooperative research project is currently supported by nine organizations from seven different member states. It is seen as an important activity and is establishing the methodology to be followed in future design and safety analysis to promote the near term deployment of HTGR nuclear power plants.

\section{EX. I-1A AND I-1B REFERENCE RESULTS: MHTGR-350}

A limited literature survey found several HTGR lattice calculation comparisons between heterogeneous and homogeneous fuel, double heterogeneity treatments (including random vs. regular particle distributions), Monte Carlo and deterministic transport codes, and continuous-energy and multi-group criticality calculations. Data sets are available for both pebble bed (Wang et al., 2014a, 2014b, Abedi and Vasoughi, 2012) and prismatic high temperature reactors (Chiang et al., 2014, Kim et al., 2013, Ilas and Gehin, 2010, Leppänen and DeHart, 2009, Žáková and Talamo, 2008), but the definition of HTGR lattice geometries varies sufficiently between these studies to preclude direct comparisons with the results reported here.

In this paper, simulations have been performed with the Monte Carlo codes Serpent (Leppänen, 2007) and SCALE/KENO-VI (ORNL, 2011) on a fresh fuel compact unit cell of the MHTRG-350, as described in Section 2. In addition to a comparison of the codes and the fuel region treatment, KENO-VI calculations for continuousenergy and two multi-group libraries have been performed, and the results obtained are compared with a sub-set of the existent body of literature. In the absence of experimental MHTGR-350 data, the results of the Serpent 
calculations are used as the reference for comparisons with the KENO-VI calculations, due to Serpent's capability to produce a continuous energy solution with a random particle distribution in the fuel cell.

\subsection{Computer Codes and Models}

The Serpent Monte Carlo Code is a three-dimensional continuous-energy neutron transport code developed at the VTT Technical Research Centre of Finland. It is capable of simulating various fuel assembly geometries, perform burn-up calculations and can also be utilized for the simulation of smaller reactor cores (Leppänen, 2007). In order to provide a better parallelization of the program and the possibility of performing threedimensional burn-up calculations, the Serpent code has recently been rewritten, and the latest version (Serpent 2) was not yet released at the time the work was performed. A beta version 2.1.21 available for licensed users were used for the calculations reported in this paper. In order to perform additional calculations using the ENDF-BVII.1 cross section data library, the source code of this version was slightly modified by the code developer, J. Leppänen. This modification was subsequently included in updated release of Serpent 2. Since Serpent 2 provides the capability of performing parallel calculations using a combination of Message Passing Interface (MPI) and Open Multi-Processing (OMP) parallelization, the calculations were performed on one of the INL High Performance Computing systems, typically utilizing 5 nodes (a total of 160 processors).

The KENO-VI module of the SCALE 6.1 code package was developed at Oak Ridge National Laboratory (ORNL). It is a high-fidelity three-dimensional Monte Carlo criticality code, and ENDF-B-VII.0 continuousenergy or 238 multi-group cross section data libraries can be applied (ORNL, 2011).

In addition to the current SCALE 6.1.2 release, results generated by two beta releases of SCALE 6.2 (beta versions 3 and 4) have also been included in this study. This version includes a new 252-group library that is optimized for LWR applications, as well as access to the latest ENDF-B-VII.1 continuous-energy cross section data library. The relative performance of these libraries for this HTGR application is also reported here. It should be noted that ORNL also developed a dedicated HTGR 81-group library in 2012 that produced very similar results compared to the 238-group library, without the latter's run-time penalty (Ellis, 2012). Unfortunately this library is not implemented in the current versions of SCALE. All SCALE calculations were performed on a single processor, and although the beta versions can be compiled to perform parallel KENO-VI computations, this option was not pursued yet.

\subsubsection{Ex. I-1a Serpent model}

The homogeneous unit cell is modeled as a two-dimensional cell with reflective boundary conditions in all directions. Cross-section data for the specified temperatures of the CZP and HFP states could directly be applied or obtained by Doppler-broadening. In terms of carbon, the natural composition of carbon was applied in all materials. Furthermore carbon was always considered as graphite, i.e. the thermal scattering data for graphite was applied. Additionally, Doppler-Broadening Rejection Correction (DBRC) for U-238 has been applied (Ouisloumen and Sanchez, 1991). All simulations were performed using the ENDF-B-VII.0 and ENDF-B-VII.1 continuous-energy cross section data libraries. For each Serpent Monte Carlo simulation, 500 active neutron cycles with 50,000 neutrons per cycle were calculated. The first 70 cycles were skipped and not considered in the evaluation of the multiplication factor. Each of the Serpent runs was typically completed within 5 minutes, using a combination of 5 MPI and 31 OMP processes.

\subsubsection{Ex. I-1a KENO-VI model}

The KENO-VI model is equivalent to the Serpent model, but extended in the axial dimension, for which the compact height $(4.928 \mathrm{~cm})$ was used. Simulations of both CZP and HFP core states using ENDF-B-VII.0 continuous-energy (CE) and multi-group (MG) cross section libraries were performed. In case of the MG cross sections, a lattice cell treatment and the 238-group library was applied. An additional calculation was performed using the 252-group library of SCALE 6.2b4. Furthermore, DBRC for ${ }^{238} \mathrm{U}$ and a problem-dependent temperature correction could be applied for the CE calculations in SCALE6.2b4. With the same settings as for the Serpent calculations, the CE KENO-VI runs with SCALE 6.1.2 typically took about 4 hours to complete on a single processor, and the respective MG calculation took about 2.5 hours. The simulations with SCALE 6.2b4 took about 6 and 3.5 hours, respectively. 


\subsubsection{Ex. I-1b Serpent model}

Exercise I-1b requires explicit modeling of the TRISO fuel particles. In order to realize an explicit model, the two-dimensional model was extended to a three-dimensional model with the height of one fuel compact. The reflective boundary condition in all directions was retained. Serpent provides the option to disperse the particles randomly in a given volume. After entering the particle specifications, the compact dimensions and the packing fraction, Serpent created a file with the positions of 6,416 randomly distributed particles in the compact (Fig. 7, left).

Additionally, a second model with particles in a regular grid was created. To distribute the particles as uniformly as possible, a layer of 128 particles in a square lattice with a pitch of $0.091 \mathrm{~cm}$ was created (Fig. 7, right). All particles are contained within the cylindrical fuel compact region, i.e. no particles were cut by the outer boundary. A stack of 50 particle layers with a height of $0.09856 \mathrm{~cm}$ each made up a fuel compact. A total of 6,400 particles are inserted in the compact in this manner (i.e., 16 particles less than in the random particle model), and the average packing fraction in the compact is therefore slightly decreased from $35 \%$ to $34.91 \%$ ). Due to larger distances between the particles and the outer cylinder boundary, the local packing fraction in one particle lattice cell increased to about $40.1 \%$. With 50,000 neutrons in 500 active and 50 skipped cycles, the simulations took about 6 minutes.
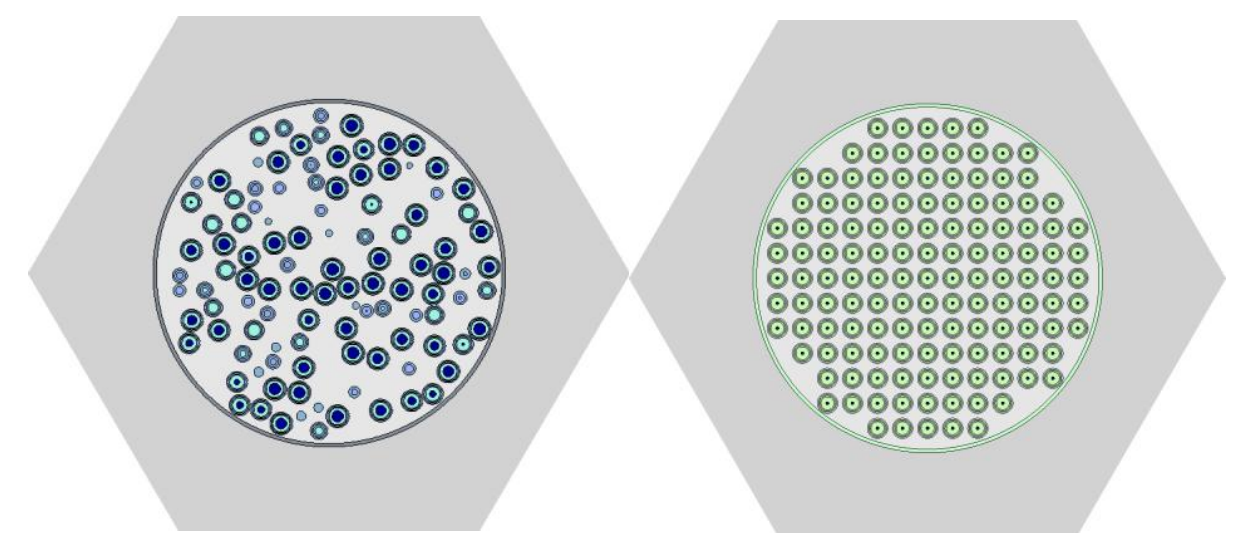

Fig. 7: Cross-sectional view of the Ex. I-1b Serpent model with randomly (left) and uniformly (right) distributed TRISO particles.

\subsubsection{Ex. I-1b KENO-VI model}

The KENO-VI model for Exercise I-1b corresponds with the Serpent model for regularly distributed TRISO particles in the compact, since the standard geometry options in KENO-VI do not include a random particle distribution. The reflective boundary condition was retained, and for the MG calculations, the DOUBLEHET cell data was specified to consider the double heterogeneous structure of the TRISO particles in the fuel compact (Williams, 2011). Using the same settings as for the Serpent calculations, the SCALE 6.1.2 CE and MG simulations took about 43 hours and 3 hours, respectively. The SCALE $6.2 \mathrm{~b} 4$ calculations again took longer with approximately 48 and 4 hours, respectively.

\subsection{Ex. I-1a Reference Results}

The term "reference" is used here in the context of the CRP scope where the eventual focus will be on the propagated uncertainties. The reference results correspond to the cases where all input parameters are set to nominal/best estimate values. To discard a sufficient number of initial neutron cycles in the Monte Carlo simulations, the convergence of the multiplication factor and the Shannon entropy of the fission source distribution (Brown, 2006) were investigated. In Fig. 8 and Fig. 9 the multiplication factor for Exercise I-1a and $1 \mathrm{~b}$ are shown as a function of the first 100 neutron cycles with 50,000 neutrons each, and in Fig. 10 the corresponding Shannon entropy is presented. The figures show that both the multiplication factor and the entropy are converged before the seventieth neutron cycle in case of Exercise I-1a, and before the fiftieth cycle 
in case of Exercise I-1b. Therefore, it is sufficient to discard the first 70 and 50 cycles, respectively. The subsequent 500 active cycles was chosen to obtain a target statistical one standard deviation error of less than $20 \mathrm{pcm}$.

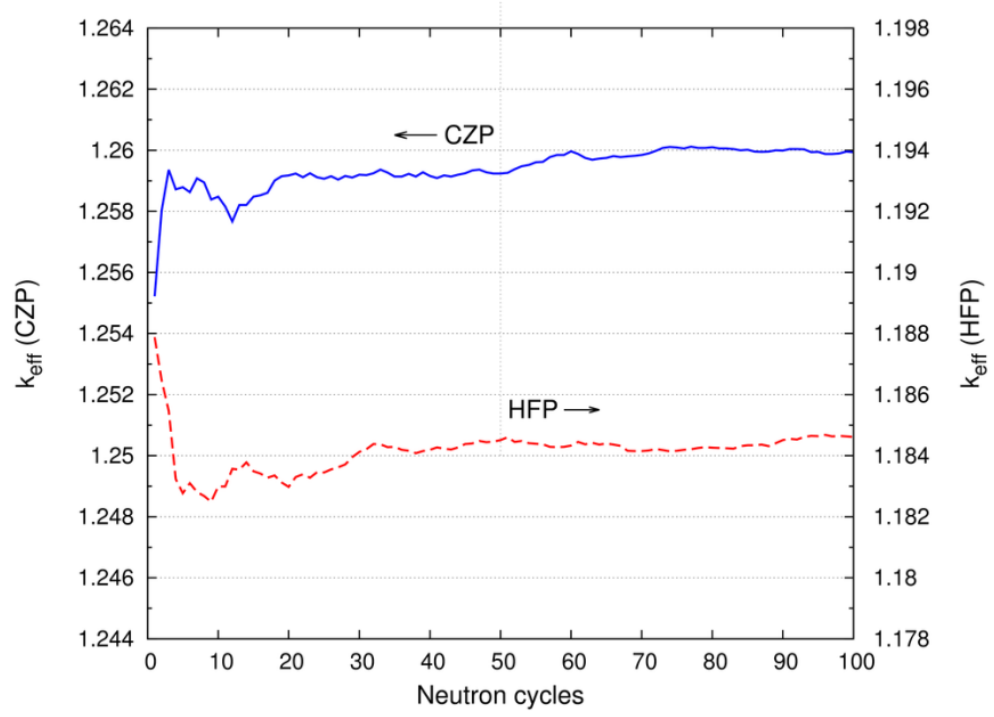

Fig. 8. Exercise I-1a multiplication factor as a function of neutron cycles (50,000 neutrons/cycle).

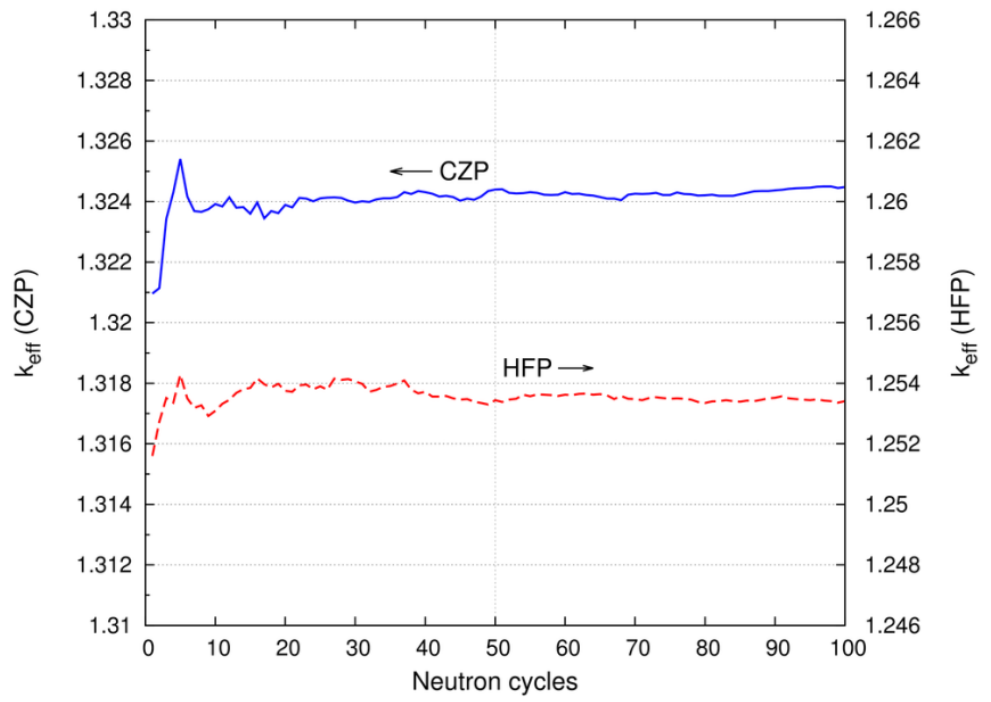

Fig. 9. Exercise I-1b multiplication factor as a function of neutron cycles (50,000 neutrons/cycle). 


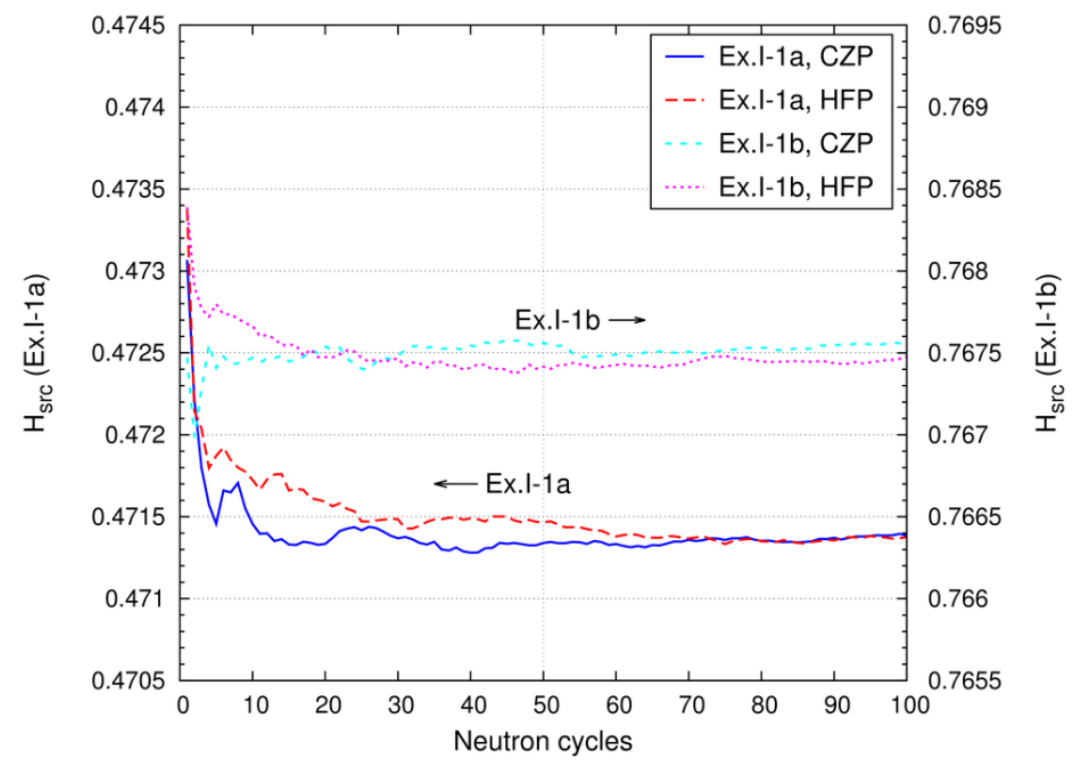

Fig. 10. Exercise I-1a/b Shannon entropy of the fission source distribution as a function of neutron cycles (50,000 neutrons/cycle).

Table 1: Serpent and SCALE/KENO-VI multiplication factors for Exercise I-1a

\begin{tabular}{|c|c|c|c|c|c|}
\hline Case & Model & $\begin{array}{l}\text { CZP } \\
\mathbf{k}_{\infty} \pm \sigma\end{array}$ & $\Delta \pm \sigma[\mathrm{pcm}]$ & $\begin{array}{l}\text { HFP } \\
\mathrm{k}_{\infty} \pm \sigma\end{array}$ & $\begin{array}{l}\Delta \pm \sigma \\
{[\mathrm{pcm}]}\end{array}$ \\
\hline 1 & Serpent: ENDF-B-VII.0 & $1.31698 \pm 0.00019$ & (reference) & $1.18245 \pm 0.00022$ & (reference) \\
\hline 2 & Serpent: ENDF-B-VII.1 & $1.31612 \pm 0.00020$ & $-86 \pm 28$ & $1.18124 \pm 0.00021$ & $-121 \pm 29$ \\
\hline 3 & KENO-VI CE (6.1.2) & $1.31576 \pm 0.00016$ & $-122 \pm 25$ & $1.18640 \pm 0.00016$ & $395 \pm 25$ \\
\hline 4 & KENO-VI CE (6.2b3) & $1.31848 \pm 0.00016$ & $150 \pm 25$ & $1.18383 \pm 0.00015$ & $138 \pm 25$ \\
\hline 5 & KENO-VI CE (6.2b3): no DBRC & $1.31885 \pm 0.00016$ & $187 \pm 25$ & $1.18994 \pm 0.00018$ & $749 \pm 27$ \\
\hline 6 & KENO-VI CE (6.2b4): ENDF-B-VII.0 & $1.31859 \pm 0.00015$ & $161 \pm 25$ & $1.18375 \pm 0.00016$ & $130 \pm 25$ \\
\hline 7 & KENO-VI CE (6.2b4): ENDF-B-VII.1 & $1.31674 \pm 0.00016$ & $62 \pm 26^{\mathrm{a}}$ & $1.18285 \pm 0.00015$ & $161 \pm 25^{\mathrm{a}}$ \\
\hline 8 & KENO-VI 238 MG (6.1.2) & $1.30897 \pm 0.00014$ & $-801 \pm 24$ & $1.18188 \pm 0.00014$ & $-57 \pm 24$ \\
\hline 9 & KENO-VI 238 MG (6.2b3) & $1.30941 \pm 0.00013$ & $-757 \pm 24$ & $1.18158 \pm 0.00013$ & $-87 \pm 24$ \\
\hline 10 & KENO-VI 252 MG (6.2b3) & $1.30912 \pm 0.00015$ & $-786 \pm 25$ & $1.18295 \pm 0.00016$ & $50 \pm 25$ \\
\hline
\end{tabular}

a. Difference with respect to Serpent ENDF-B-VII.1value

The results of Exercise I-1a are summarized in Table 1. Although the ENDF-B-VII.1 data library is the latest release, the Serpent result using the ENDF-B-VII.0 library (Case 1) is taken as the reference result for this comparison. This allows a meaningful comparison with most of the KENO-VI results, since only version $6.2 \mathrm{~b} 4$ (Case 7) can apply the ENDF-B-VII.1 cross section data. It is observed that the use of the ENDF-B-VII.1 data in Case 2 lead to infinite multiplication factors $\left(\mathrm{k}_{\infty}\right) 86 \mathrm{pcm}$ lower than the ENDF-B-VII.0 values in Case 1. A somewhat larger effect is noted when the latest beta release KENO-VI CE results are compared for the two libraries (Cases 6 and 7 differ by approximately $180 \mathrm{pcm}$ and $90 \mathrm{pcm}$ for the cold and hot cases, respectively). Goto (2011) ascribed these differences to an underestimation of the carbon neutron capture cross section at thermal energies in the ENDF-B-VII.0 library. The correction of this cross section in ENDF-B-VII.1 resulted in increased neutron capture and thus a reduction in the multiplication factor. The HFP $\mathrm{k}_{\infty}$ are furthermore up to $13500 \mathrm{pcm}$ lower than the CZP $\mathrm{k}_{\infty}$ values of the Serpent calculations. These differences are a primarily the result of ${ }^{238} \mathrm{U}$ Doppler resonance broadening. 
The KENO-VI 6.1.2 CE calculation (Case 3) of the CZP $\mathrm{k}_{\infty}$ is $122 \mathrm{pcm}$ lower than the Serpent reference result, but the hot state $\mathrm{k}_{\infty}$ is overestimated by $395 \mathrm{pcm}$. The KENO-VI $6.2 \mathrm{~b} 3$ and $6.2 \mathrm{~b} 4 \mathrm{CE}$ calculations (Cases 4 and 6) revealed differences of $150 / 138 \mathrm{pcm}$ and $161 / 130 \mathrm{pcm}$ for the cold and hot cases, respectively. The model for the Serpent and KENO CE calculations are identical. Therefore, it can be concluded that the differences between the SCALE and Serpent results are primarily caused by differences in processing of the applied ENDF data libraries: SCALE utilizes its own processed AMPX format libraries, while the ACE-formatted cross-section libraries of Monte Carlo N-Particle (MCNP) were applied for the Serpent calculations.

It is furthermore noticed that, in contrast to Case 3, the differences between Cases 4 and 6 and the Serpent reference are in the same range for both states. This improvement can be ascribed to the application of the new DBRC method implemented as a new capability in KENO-VI version 6.2b3 (Rearden, 2013). A test calculation without the application of DBRC for ${ }^{238} \mathrm{U}$ (Case 5) revealed that this correction leads to a decrease of the multiplication factor by $37 \mathrm{pcm}$ in the cold case and $611 \mathrm{pcm}$ in the hot case through the inclusion of ${ }^{238} \mathrm{U}$ up-scattering and the resultant increase in resonance absorption. The temperature dependence of this correction is also clearly shown by these comparisons.

The 238 group multiplication factors of KENO-VI 6.1.2 (Case 8) and 6.2b3 (Case 9) only differ by 44 pcm. The CZP MG calculations of both versions underestimate the reference $\mathrm{k}_{\infty}$ by approximately $800 \mathrm{pcm}$, but the hot cases show a much better agreement with Serpent (within $90 \mathrm{pcm}$ ). The KENO-VI $6.2 \mathrm{~b} 3$ calculation with 252 groups (Case 10) shows overlapping error bars with the other MG calculations for the cold state, and the multiplication factor of the hot case $\mathrm{k}_{\infty}$ is within $50 \mathrm{pcm}$ of the reference Serpent value. Although some differences are observed between the results of the KENO-VI 252 and 238 group libraries, the agreement with Serpent did not improve significantly. This result could be expected from the fact that the 252 group library was optimized for use in water-moderated LWR applications as opposed to these graphite-moderated HTGR lattice applications.

\subsection{Ex. I-1b Reference Results}

The results of Ex. I-1b are summarized in Table 2. Case 1, the Serpent model including the random particle distribution using ENDF-B-VII.0 cross sections, is again used as the reference. The difference between the Serpent calculations using different ENDF-B-VII data libraries, i.e. between Case 1 and 2, is slightly larger compared to the trends observed for Ex. I-1a.

Table 2: Serpent and SCALE/KENO-VI multiplication factors for Exercise I-1b

\begin{tabular}{|c|c|c|c|c|c|}
\hline \multirow[b]{2}{*}{ ঠ్ల } & \multirow[b]{2}{*}{ Model } & \multicolumn{2}{|l|}{ CZP } & \multicolumn{2}{|c|}{ HFP } \\
\hline & & $\mathrm{k}_{\infty} \pm \sigma$ & $\begin{array}{l}\Delta \pm \sigma \\
{[\mathrm{pcm}]}\end{array}$ & $\mathbf{k}_{\infty} \pm \sigma$ & $\begin{array}{c}\Delta \pm \sigma \\
[\mathrm{pcm}])\end{array}$ \\
\hline 1 & Serpent - random: ENDF-B-VII.0 & $1.37060 \pm 0.00021$ & (ref.) & $1.24461 \pm 0.00023$ & (ref.) \\
\hline 2 & Serpent - random: ENDF-B-VII.1 & $1.36899 \pm 0.00021$ & $-161 \pm 30$ & $1.24335 \pm 0.00024$ & $-126 \pm 32$ \\
\hline 3 & Serpent - reg. lattice: ENDF-B-VII.0 & $1.37642 \pm 0.00021$ & $582 \pm 30$ & $1.25071 \pm 0.00024$ & $610 \pm 32$ \\
\hline 4 & KENO-VI CE - reg. lattice (6.1.2) & $1.37276 \pm 0.00015$ & $\begin{array}{l}216 \pm 26 \\
-366 \pm 26^{\mathrm{a}}\end{array}$ & $1.25264 \pm 0.00018$ & $\begin{array}{l}803 \pm 280 \\
193 \pm 30^{\text {a }}\end{array}$ \\
\hline 5 & KENO-VI CE - reg. lattice (6.2b3) & $1.37480 \pm 0.00015$ & $\begin{array}{l}420 \pm 20 \\
-162 \pm 22^{a}\end{array}$ & $1.25164 \pm 0.00016$ & $\begin{aligned} 703 & \pm 27 \\
93 & \pm 25^{a}\end{aligned}$ \\
\hline 6 & $\begin{array}{l}\text { KENO-VI CE - reg. lattice (6.2b3): no } \\
\text { DBRC }\end{array}$ & $1.37505 \pm 0.00015$ & $\begin{aligned} 445 & \pm 26 \\
25 & \pm 26^{b}\end{aligned}$ & $1.25811 \pm 0.00015$ & $\begin{array}{l}1350 \pm 26 \\
647 \pm 22^{b}\end{array}$ \\
\hline 7 & $\begin{array}{l}\text { KENO-VI CE - reg. lattice }(6.2 \mathrm{~b} 4): \\
\text { ENDF-B-VII.0 }\end{array}$ & $1.37731 \pm 0.00015$ & $\begin{aligned} 671 & \pm 26 \\
89 & \pm 22^{a}\end{aligned}$ & $1.25158 \pm 0.00017$ & $\begin{aligned} 697 & \pm 28 \\
87 & \pm 23\end{aligned}$ \\
\hline 8 & $\begin{array}{l}\text { KENO-VI CE - reg. lattice (6.2b4): } \\
\text { ENDF-B-VII.1 }\end{array}$ & $1.37599 \pm 0.00015$ & $700 \pm 26^{c}$ & $1.25044 \pm 0.00015$ & $709 \pm 26^{c}$ \\
\hline 9 & KENO-VI 238 MG/DOUBLEHET (6.1.2) & $1.36162 \pm 0.00015$ & $-898 \pm 26$ & $1.24202 \pm 0.00013$ & $-259 \pm 25$ \\
\hline 10 & KENO-VI 238 MG/DOUBLEHET (6.2b3) & $1.36367 \pm 0.00013$ & $-693 \pm 25$ & $1.24350 \pm 0.00014$ & $-111 \pm 26$ \\
\hline 11 & KENO-VI 252 MG/DOUBLEHET (6.2b3) & $1.36361 \pm 0.00013$ & $-699 \pm 25$ & $1.24475 \pm 0.00015$ & $14 \pm 26$ \\
\hline
\end{tabular}

a. Difference with respect to Serpent lattice (ENDF-B-VII.O) result. b. Difference with respect to KENO-VI CE reg. lattice (6.2b3) result. c. Difference with respect to Serpent random (ENDF-B-VII.1) result. 
The Serpent calculation with the regular particle lattice (Case 3) reveals a significant overestimation of $\mathrm{k}_{\infty}$ about $610 \mathrm{pcm}$ compared to the random model. Similar studies for prismatic HTGR lattice problems (Leppänen and DeHart, 2009, Žáková and Talamo, 2008), however, reported conflicting trends. The particle lattice is a simplification of the actual random particle distribution in a compact, and deviations from a random distribution are caused by the lattice arrangement (i.e., the lattice pitch, mass conservation of the fuel [important if particles are cut by the outer compact surface] and the packing fraction). The local packing fraction in the "particle unit cell" is increased compared to the average fraction, which leads to an increase in the multiplication factor. A Serpent calculation using the random particle distribution with 6,400 TRISO particles was also performed to obtain the influence of the slightly smaller amount of fuel in the particle lattice model (this variant is not included in Table 2). The difference between the calculations of 6,400 and 6,416 particles is $112 \mathrm{pcm}$ in the cold case and $69 \mathrm{pcm}$ in the hot case. This small difference in the amount of fuel is therefore not solely responsible for the large difference observed compared to the reference calculation.

For a better code-to-code comparison the CE KENO-VI results for Case 4 are compared to both the Serpent lattice model (Case 3) and the reference Serpent random model results (Case 1). The KENO-VI 6.1.2 simulation showed differences of 216 and $803 \mathrm{pcm}$ to the random model for the cold and hot states, respectively. The agreement between the Serpent and CE KENO-VI lattice models improved significantly for the HFP case (from $803 \mathrm{pcm}$ to $193 \mathrm{pcm}$ ), but decreased for the CZP case (from $216 \mathrm{pcm}$ to $-366 \mathrm{pcm}$ ). Similar trends can be observed between the various versions of SCALE, with KENO-VI 6.2b4 (Case 7) producing the best-matched set of lattice results with Serpent (less than $90 \mathrm{pcm}$ differences for both cold and hot cases). The significant improvement in especially the hot case is again mainly caused by the application of the DBRC method $(647 \mathrm{pcm}$ for Case 6), as already noted in the previous exercise.

All KENO-VI MG calculations (Cases 9-11) underestimate the reference by several hundred pcm, but better agreement exists at HFP conditions. The 252 group HFP calculation produced a much smaller difference of only $14 \mathrm{pcm}$, and as noted previously, the KENO-VI $6.2 \mathrm{~b} 3$ calculations using 252 groups (Case 11) are again the closest to the reference Serpent values. The differences to the Serpent reference are again caused by differently processed ENDF data for Serpent and SCALE, and also by approximations in the multi-group calculations. For the self-shielding calculation for example, the double-heterogeneity (the DOUBLEHET cell) was realized by a two-pass scheme in which the particles in the compact are treated first, followed by the treatment of the compact level within the lattice. The randomness effect could not be considered in KENO-VI in the same way as it was applied in the Serpent calculations. No multi-group results are available for KENO-VI 6.2b4, since the double heterogeneous treatment was disabled in this SCALE version.

The trend of MG under-estimating CE calculations was also observed by Chiang (2014), Wang (2012), and Ilas (2010) for the criticality calculations of the HTTR, a prismatic high temperature reactor with annular fuel compacts. The regular particle lattice fuel compact simulations of Leppänen (2009), however, produced better agreement between KENO-VI and Serpent. Since the assumed fuel and graphite temperatures might have a significant influence on this difference, and Leppänen did not include temperature-related information, a final conclusion cannot be reached at this point.

\subsection{Comparison of Ex. I-1a and Ex. I-1b}

The main differences between Ex. I-1a and $1 \mathrm{~b}$ are presented in Table 3. The simulation of the homogeneous fuel region with Serpent underestimates the reference (explicit TRISO) result by between 5,362 pcm and 6,273 $\mathrm{pcm}$, depending on the assumed temperature. In this case, the fuel is homogeneously mixed with the graphite matrix with the result of increased neutron capture in ${ }^{238} \mathrm{U}$ due to the missing self-shielding effect. A similar (but slightly larger) result was observed by Kim (2013) who found differences of about 6,800 pcm at $600 \mathrm{~K}$ and about $7,000 \mathrm{pcm}$ at $1,000 \mathrm{~K}$ in KENO-VI MG and McCARD CE calculations of a single HTGR fuel pin. Wang (2012) also reported a difference of $5,500 \mathrm{pcm}$ in comparing a KENO-VI MG lattice calculation using an infinite homogenous medium unit-cell with a heterogeneous particle lattice CE calculation of the HTTR.

Table 3: Comparison between Exercise I-1a and I-1b

\begin{tabular}{|c|rr|rr|}
\hline Model & $\mathrm{k}_{\infty} \pm \sigma$ & $\mathrm{k}_{\infty} \pm \sigma$ & \multicolumn{3}{c|}{ CZPP } & $\Delta \pm \sigma[\mathrm{pcm}]$ \\
\hline
\end{tabular}




\begin{tabular}{|l|cc|cc|}
\hline $\begin{array}{l}\text { Serpent - random (ENDF-B-VII.0) } \\
\text { heterogeneous }\end{array}$ & $1.37060 \pm 0.00021$ & (reference) & $1.24461 \pm 0.00023$ & (reference) \\
$\begin{array}{l}\text { Serpent (ENDF-B-VII.0): homogeneous } \\
\text { KENO-VI CE (6.1.2): homogeneous }\end{array}$ & $1.31698 \pm 0.00019$ & $-5362 \pm 29$ & $1.18245 \pm 0.00022$ & $-6216 \pm 32$ \\
KENO-VI 238 MG (6.1.2): homogeneous & $1.31576 \pm 0.00016$ & $-5484 \pm 27$ & $1.18640 \pm 0.00016$ & $-5821 \pm 29$ \\
\hline
\end{tabular}

The normalized neutron flux in the Serpent unit cell is presented in Fig. 11. The lower thermal peak in the homogeneous case (red line) is due to the neglect of the self-shielding effect and the resultant increase in the ${ }^{238} \mathrm{U}$ resonance absorption. The spectrum shift of the thermal peak value from the cold (green line) to the hot state (blue line) is also clearly visible. A comparison of the ${ }^{238} \mathrm{U}$ capture cross section is presented in Fig. 12 for three cases. The homogeneous calculation shows significant differences of more than $15 \%$ in the resonance region, while the CZP and HFP variances in the Ex. I-1b lattice calculation are relatively small $(<3 \%)$.

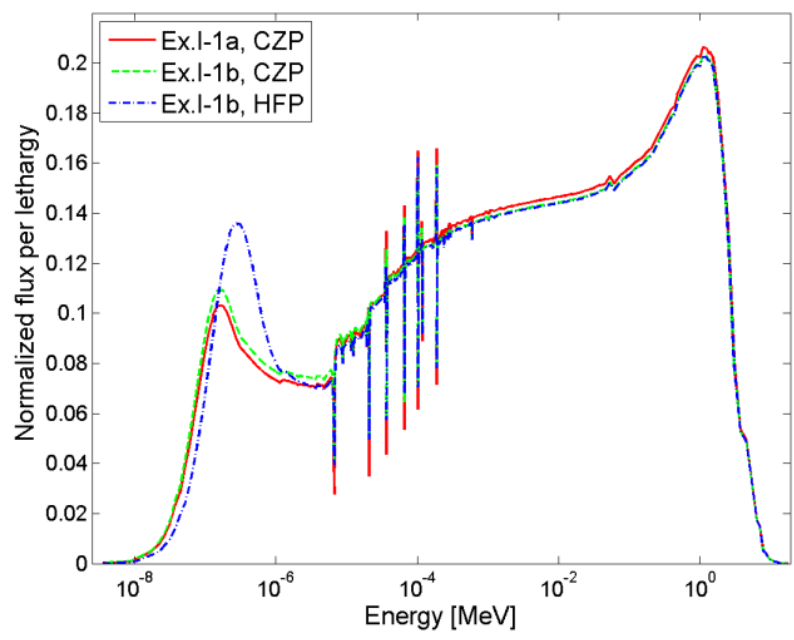

Fig. 11: Normalized neutron flux in the fuel compact unit cell.

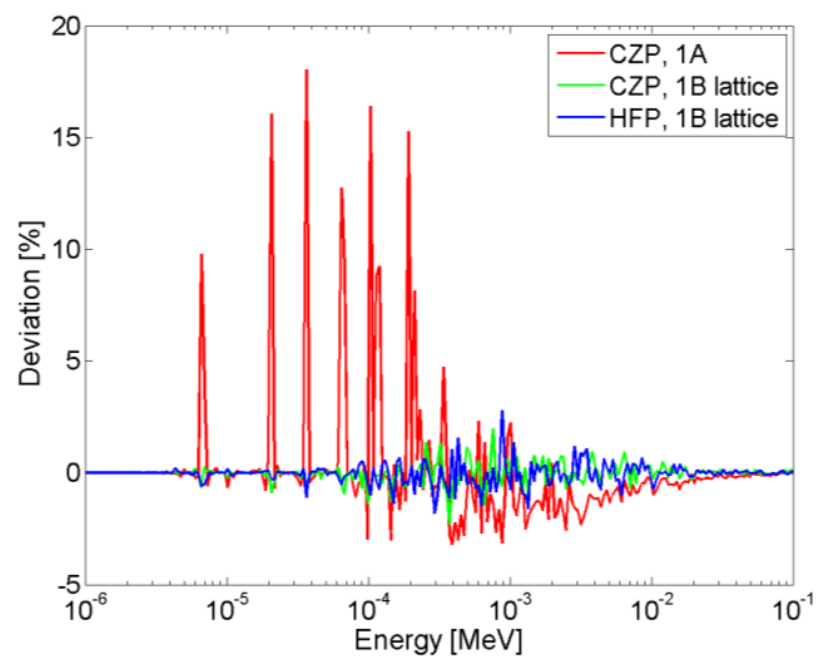

Fig. 12: Differences (\%) in the ${ }^{238} \mathrm{U}$ capture cross sections in the fuel compact unit cell for the Ex. I-1a and I-1b compared to Serpent calculations utilizing random particle distributions. 
It is interesting that the fast flux peak is higher than the thermal peak for both fuel compact models in Fig. 11. It has to be noted that only a unit cell is calculated in this exercise, not a block or a full reactor core. The moderator-to-fuel ratio in this cell is therefore small in comparison with the fuel block, which includes additional graphite in the center, in cells with helium channels and on the outer edges of the block (cf. Section 2). If the block graphite density of the cell is increased to match the moderator-to-fuel ratio of a fuel block without burnable poison, similar unit cell and block flux shapes can be obtained (Fig. 13). The increased graphite density leads to better moderation and therefore a comparatively higher thermal peak. A similar unit cell spectrum (to the one used in this study) has also been used by Ellis (2012) in a very detailed 999 fine-group cell-weighted calculation.

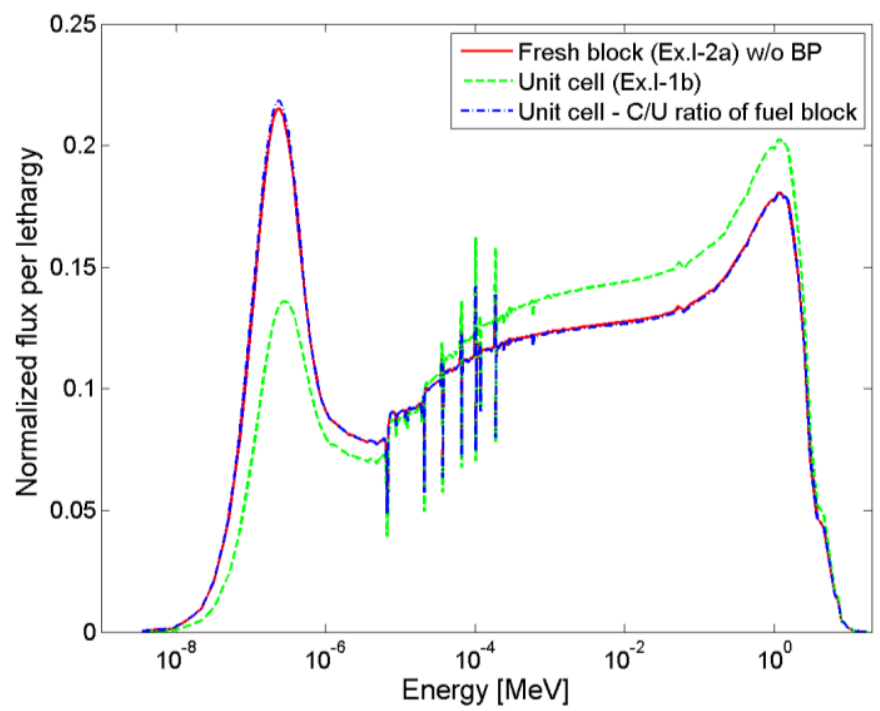

Fig. 13. Normalized neutron flux in the unit cell of Exercise I-1b with modified moderator-fuel-ratio.

\subsection{Influence of the Graphite Thermal Scattering Library}

During this investigation, the question of the treatment of carbon or graphite in the different materials arose. If the thermal scattering library for graphite is applied, a graphite crystal is assumed. In the case of the UCO fuel particle and the silicon carbide layer, carbon does not form a graphite crystal. The treatment of carbon as graphite in these materials might be wrong, and the treatment of other materials containing only graphite is also questionable. Hawari and Gillete (2014) stated that reactor grade graphite should not be assumed to be an ideal single crystal. They considered the porosity of graphite in a calculation of the thermal neutron scattering cross sections for graphite. Swanson and Harrison (1988) suggested modeling graphite structures as a mixture of crystalline-bound graphite and amorphous carbon as a better representation of the actual material.

To estimate the uncertainty that may be introduced by these assumptions, three additional calculations based on Swanson and Harrison's suggestion were performed with Serpent: (1) the carbon in all materials was treated as graphite, (2) only the carbon in UCO and the silicon carbide layer was not treated as graphite, and (3) carbon in all materials was treated as a mixture of $80 \%$ graphite and $20 \%$ elemental carbon. The material mixture of the last case was chosen arbitrarily. It highly overestimates the amount of amorphous carbon and should therefore indicate if there is a relevant influence of the carbon treatment. Simulations of Exercise I-1b were performed with both the random particle distribution and the particle lattice, but only the results of the simulations with random particle distributions are provided in Table 4 due to space considerations. Case (2) showed minor differences in $\mathrm{k}_{\infty}$ (mostly in the order of one standard deviation and not above $0.05 \%$ ) compared to case (1). The multiplication factor of Case (3) overestimates Case (1) by up to $149 \mathrm{pcm}$ or $0.15 \%$, but a comparison of these differences did not show a specific bias.

A mixture of graphite and amorphous carbon is not a straightforward modification in the Serpent input. Furthermore, the treatment of carbon in the homogeneous fuel region of Exercise I-1a and in the homogenized burned fuel block of the super cell in ExerciseI-2c (Fig. 6) would also have to be modified if Case (2) or (3) 
would be applied. Given the rather small differences between these cases, the error introduced by assuming $100 \%$ graphite in all carbonaceous materials is considered negligible for the purposes of this benchmark. Therefore, in all calculations in this study, $100 \%$ graphite is used in all carbonaceous structures.

Table 4. Comparison of three Exercise I-1b variants (Serpent random particle distribution).

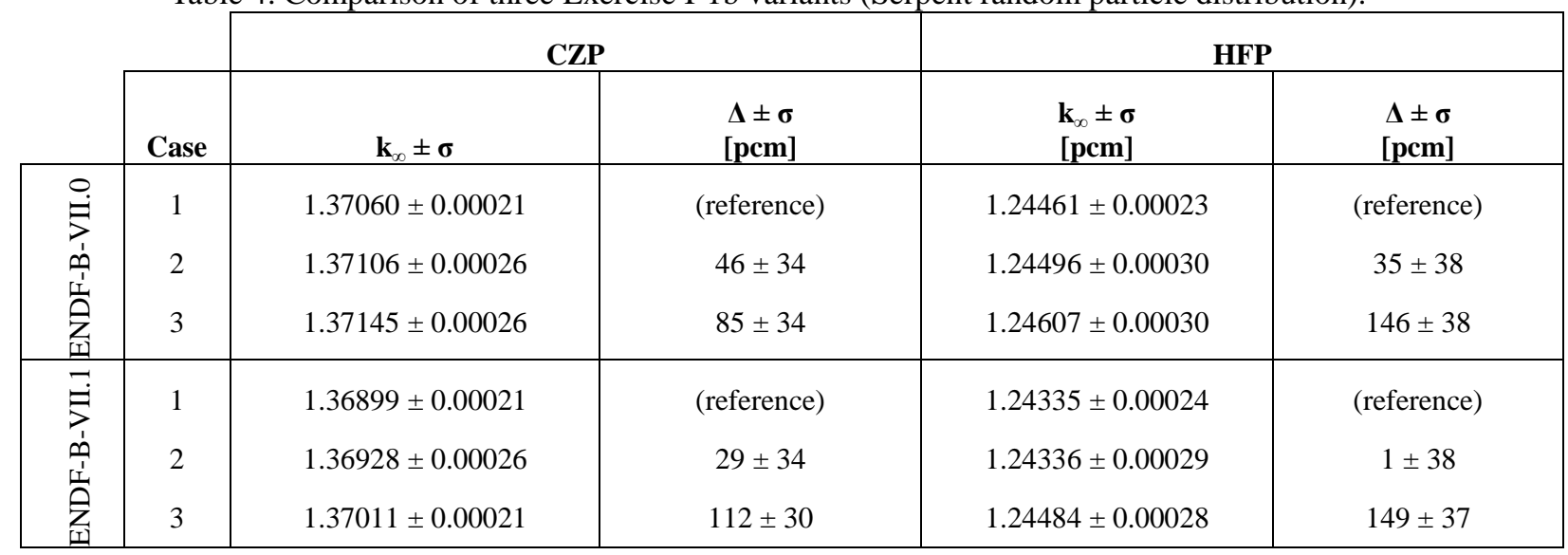

\section{SCALE/TSUNAMI CROSS-SECTION UNCERTAINTY RESULTS FOR EX. I-1A (HFP)}

In addition to the reference "nominal case" results discussed in Section 3 for the prismatic design, the first uncertainty assessment results obtained for the HFP variant of Ex. I-1a with SCALE/TSUNAMI (Tools for Sensitivity and Uncertainty Analysis Methodology Implementation) (ORNL, 2011) are presented here. The TSUNAMI module utilizes data from the forward and adjoint transport solutions in an adjoint perturbation theory approach to generate sensitivity and uncertainty information. A cross-section library of covariance matrices for 401 nuclides in a 44-group energy structure are used to calculate the uncertainty on the integral parameters of interest (e.g. $\mathrm{k}_{\infty}$ ).

All the calculations presented here were performed with SCALE 6.1.2, but a new super-sequence SAMPLER (Williams, 2012) has also been developed for the beta releases of SCALE 6.2, and the result obtained with TSUNAMI will be compared in future work. Since the current versions of TSUNAMI is not capable of generating data for systems that use the DOUBLEHET cell models (as would be required for Ex. I-1b and all subsequent HTGR exercises), the use of SAMPLER is the only method available in SCALE that can provide the correct implicit and explicit sensitivity coefficients. The explicit sensitivity coefficients are determined from the flux perturbation that resulted from the perturbation of the multi-group cross sections, while the implicit sensitivity coefficients are associated with spectral perturbations; i.e. a perturbation in the cross section of a nuclide could change the self-shielded cross section of another nuclide, which in turn leads to additional flux perturbations.

Although it is well-known that the correct heterogeneous treatment for HTGR designs is a basic modelling requirement, it was nevertheless decided to include Ex. I-1a as the first exercise to assess the differences that might result from this approach. Using the same homogeneous unit cell definition as described in the previous section, KENO-VI obtained a forward best-estimate $\mathrm{k}_{\infty}=1.18152 \pm 0.00015$ for the HFP variant of Ex. I- $1 \mathrm{a}$, using $25 \times 10^{6}$ neutron histories (550 generations, 70 skipped, 50,000 neutrons per generation). The adjoint KENO-VI calculation simulated $75 \times 10^{6}$ neutron histories $(650 / 150 / 150,000)$ to obtain an adjoint best-estimate $\mathrm{k}_{\infty}=1.18280 \pm 0.00270$. The difference between the forward and adjoint solutions $(128 \mathrm{pcm})$ is within the SCALE/TSUNAMI guidelines for use in the subsequent uncertainty and sensitivity assessment.

In the next uncertainty quantification step, the SCALE/SAMS module utilised the forward and adjoint flux data set to calculate a HFP $\mathrm{k}_{\infty}$ relative standard deviation of $\sigma=0.5786 \pm 0.0002 \% \Delta \mathrm{k} / \mathrm{k}$ due to the cross-section covariance data. The $\mathrm{k}_{\infty}$ relative standard deviation is obtained by adding the square of the positive value contributions from the individual covariance matrices quadratically, and subtracting the square of the values with negative signs. In addition, independence is assumed between these contributors. The nuclide reaction 
covariance matrices responsible for the five largest contributions to the uncertainties in the HFP k-inf data are listed in Table 5. The largest $\mathrm{k}_{\infty}$ uncertainty contributor is the ${ }^{238} \mathrm{U}(\mathrm{n}, \gamma)$ (capture) reaction, followed by the ${ }^{235} \mathrm{U}(\bar{v})$ and ${ }^{235} \mathrm{U}(\mathrm{n}, \gamma)$ reactions. (Here, $\bar{v}$ is the average number of neutrons per fission reaction). The data for the CZP case is similar and not included here.

The total uncertainty can be obtained by adding the statistical sampling uncertainty obtained from the forward Monte Carlo result $(0.013 \% \Delta \mathrm{k} / \mathrm{k})$ to the uncertainty contributions from the covariance data, using the RSS method (Root of Sum of Squares). In this case, we obtain $\sqrt{0.013^{2}+0.5786^{2}}=0.5787$ as the total $k_{\infty}$ standard deviation.

Table 5: Top 5 nuclide reaction covariance contributors to $\mathrm{k}_{\infty}$ uncertainty - Ex. I-1a HFP

\begin{tabular}{|l|l|c|}
\hline Rank & Nuclide reaction pair & $\begin{array}{l}\text { Uncertainty contribution due } \\
\text { to this matrix }(\boldsymbol{\%} \mathbf{\Delta} \mathbf{k} \mathbf{k})\end{array}$ \\
\hline 1 & ${ }^{238} \mathrm{U}(\mathrm{n}, \gamma) /{ }^{238} \mathrm{U}(\mathrm{n}, \gamma)$ & 0.398 \\
2 & ${ }^{235} \mathrm{U}(\bar{v}) /{ }^{235} \mathrm{U}(\bar{v})$ & 0.261 \\
3 & ${ }^{235} \mathrm{U}(\mathrm{n}, \gamma) /{ }^{235} \mathrm{U}(\mathrm{n}, \gamma)$ & 0.256 \\
4 & C-graphite elastic / C-graphite elastic & 0.128 \\
5 & $\mathrm{U}-238$ elastic / U-238 elastic & 0.124 \\
\hline $\mathrm{k}_{\infty}$ standard deviation due to nuclide reaction & 0.5786 \\
covariance data & 0.013 \\
\hline $\mathrm{k}_{\infty}$ statistical standard deviation due to Monte \\
Carlo sampling (from KENO-VI forward \\
solution) \\
\hline \multicolumn{2}{|l|}{ Total $\mathrm{k}_{\infty}$ standard deviation } \\
\hline
\end{tabular}

The contributions reported here for the homogenous prismatic HTGR unit cell is similar to the results obtained by for the equivalent cell exercises defined for Phase I of the OECD LWR UAM benchmark (Ivanov, 2013). Mercatali (2013) reports total uncertainties in $\mathrm{k}_{\infty}$ varying between $0.5 \%$ and $0.6 \%$ for these thermal systems. The differences between the HTGR and LWR/BWR Phase I results are in the relative importance of the $\mathrm{C}$-graphite and ${ }^{238} \mathrm{U}$ elastic scattering contributions, as can be expected from a graphite moderated thermal system.

The sensitivity profiles for the ${ }^{238} \mathrm{U}(\mathrm{n}, \gamma),{ }^{235} \mathrm{U}(\bar{v}),{ }^{235} \mathrm{U}(\mathrm{n}, \gamma)$ and ${ }^{238} \mathrm{U}$ elastic scattering reactions are shown in Fig. 14 and Fig. 15. The contributions of the ${ }^{238} \mathrm{U}$ resonance region cross-sections can clearly be observed. The integral values indicated in the legends of the figures are the $\%$ change in $\mathrm{k}_{\infty}$ for a $1 \%$ increase in the respective nuclide cross-section, applied to all energy groups. For example, in Fig. 14 it is shown that a $1 \%$ increase in the ${ }^{235} \mathrm{U}(\mathrm{n}, \gamma)$ cross-section would lead to a change in $\mathrm{k}_{\infty}$ of $-0.203 \%$, while the same change in the ${ }^{238} \mathrm{U}$ elastic crosssection would only change $\mathrm{k}_{\infty}$ by $0.031 \%$. 


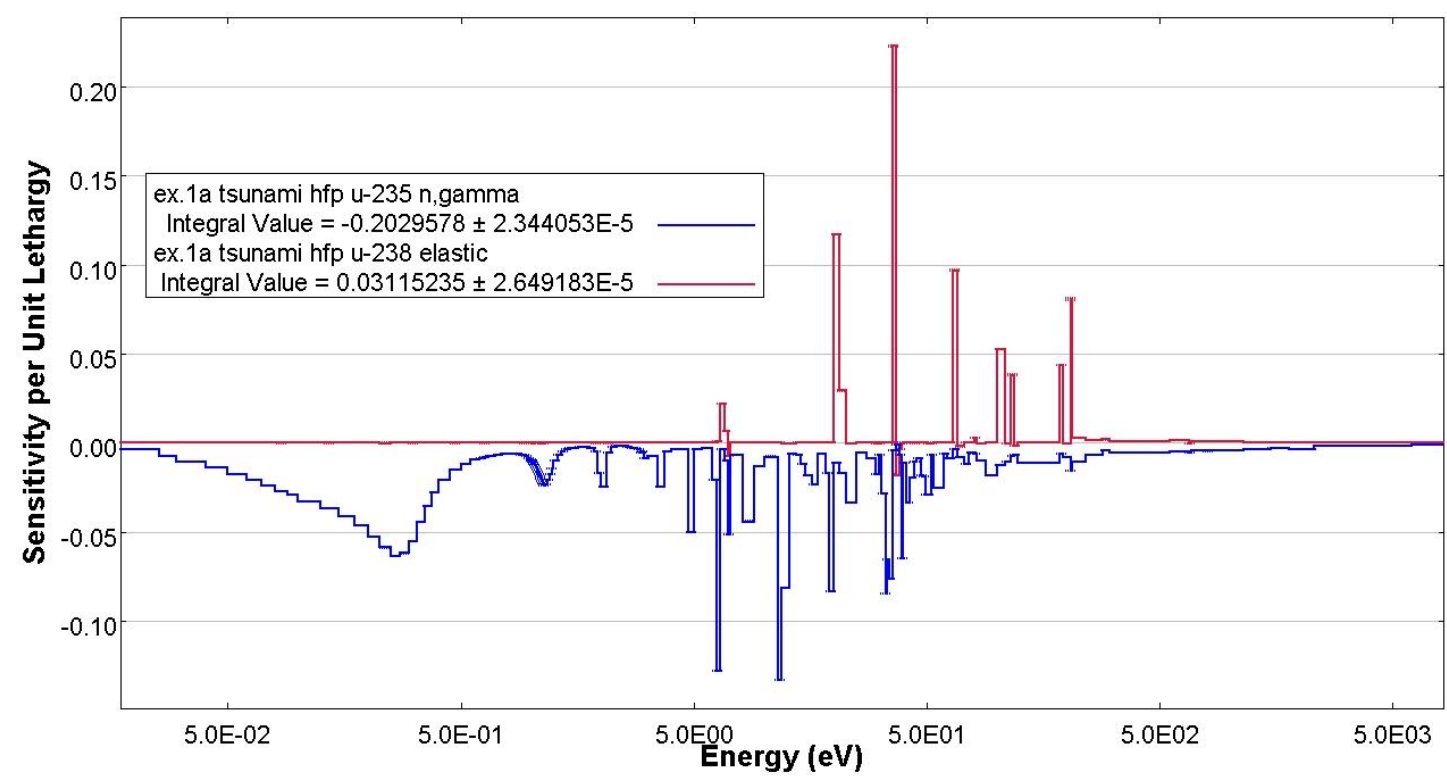

Fig. 14: $\mathrm{k}_{\infty}$ Sensitivity profiles for the ${ }^{235} \mathrm{U}(\mathrm{n}, \gamma)$ and ${ }^{238} \mathrm{U}$ elastic scattering covariance matrices.

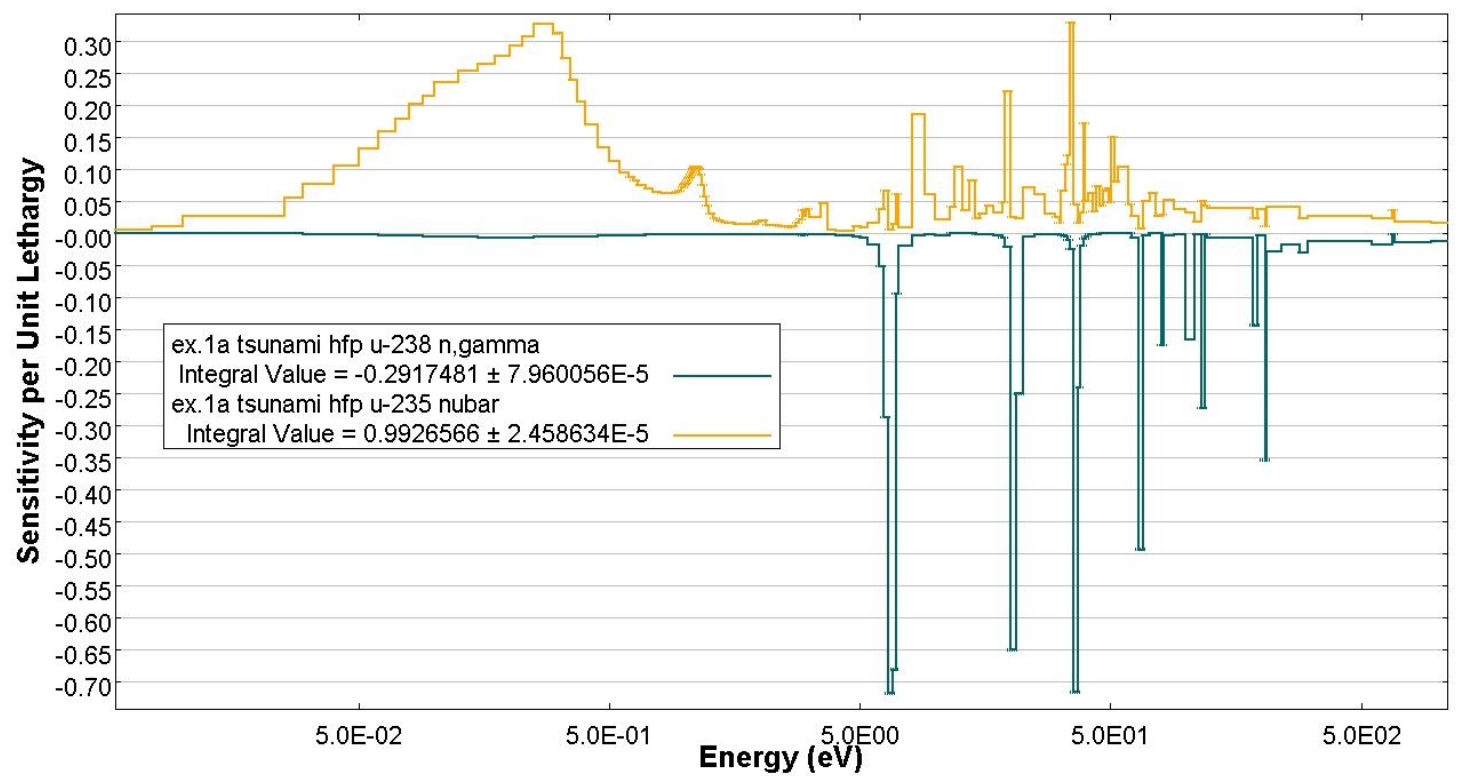

Fig. 15: $\mathrm{k}_{\infty}$ Sensitivity profiles for the ${ }^{238} \mathrm{U}(\mathrm{n}, \gamma)$ and ${ }^{235} \mathrm{U}(\bar{v})$ covariance matrices.

\section{SUMMARY AND FUTURE WORK}

The Coordinated Research Programme on the uncertainties in HTGR coupled code modelling is a natural and logical continuation of previous international HTGR V\&V activities. This paper presented an overview of the CRP current status, as well as the first results for Exercises 1a and $1 \mathrm{~b}$ of Phase 1 for the prismatic test cases. Reasonable agreement was found between the Serpent and SCALE/KENO-VI Monte Carlo codes on the calculation of the reference results for the nominal Cold Zero and Hot Full Power cases, and the results of various sensitivity studies were also presented. The main contributors to the uncertainty in $\mathrm{k}_{\infty}$ were identified as the ${ }^{238} \mathrm{U}(\mathrm{n}, \gamma)$ (capture) and ${ }^{235} \mathrm{U}(\bar{v})$ cross-section covariance matrices, and the total (one sigma) $\mathrm{k}_{\infty}$ uncertainty attributed to all cross-section covariances was found to be $0.58 \%$ for the HFP case. 
The successful completion of the CRP on HTGR UAM is dependent on the availability of tools, software and data. The fourth beta release of SCALE 6.2 in June 2014 allowed the exploration of updated (KENO, TSUNAMI) and new (SAMPLER) tools, but the lack of the double heterogeneous treatment in this version implied that only the Continuous Energy cases could be investigated. In the case of HTGR systems that require the treatment of double heterogeneity, the availability of the updated stochastic sequence SAMPLER that includes this treatment is of specific interest to the HTGR community.

In 2016, scheduled CRP activities include the publication of updated Phase I and II specifications for the pebble bed and prismatic designs, as well as the third Research Coordination Meeting. Future work will involve the extension of these fuel compact unit cell models to fresh and depleted single and supercell fuel block models, as discussed in Section 2, and the development of reference and uncertainty data sets for these models. As the propagation of uncertainties through the subsequent coupled core stage requires few-group transport solutions, work has already started on using the NEWT transport solver in SCALE to create equivalent cell, block, and super-cell multi-group lattice models, and to compare the results with the Monte Carlo results reported here.

For an experimental validation of the prismatic exercises, measured data of the VHTRC critical assembly (OECD/NEA, 2008) was compared with the results obtained from Serpent and SCALE simulations (Bostelmann, 2016), and the uncertainty and sensitivity analyses will be completed in 2016 . For the pebble bed design, one of the ASTRA facility critical experiments with measured reactor physics parameters (OECD/NEA, 2014) will be considered as the representative experiment, especially since detailed material and experimental uncertainties are also available that will facilitate detailed uncertainty comparisons.

\section{ACKNOWLEDGEMENTS}

This work was prepared for the U.S. Department of Energy (Office of Nuclear Energy) under DOE Idaho Operations Office Contract DE-AC07-05ID14517.

\section{REFERENCES}

A. Abedi, N. Vasoughi, "Neutronic simulation of a pebble bed reactor considering its double heterogeneous nature", Nuclear Engineering and Design, Vol. 253, pp. 277-284 (2012).

F. Bostelmann, et al., "Criticality calculations of the Very High Temperature Reactor Critical Assembly benchmark with Serpent and SCALE/KENO-IV”, Annals of Nuclear Energy (in publication).

F. B. Brown, "On the use of shannon entropy of the fission distribution for assessing convergence of Monte Carlo criticality calculations," Proc. of PHYSOR-2006, ANS Topical Meeting on Reactor Physics, Vancouver, Canada, September 10-14, 2006.

M.-H. Chiang, et al., "Evaluation of the HTTR criticality and burnup calculations with continuous-energy and multigroup cross sections", Nuclear Engineering and Design, Vol. 271, pp. 327-331 (2014).

R. J. Ellis, et al., "Generation of a broad-Group HTGR library for use with SCALE", NUREG/CR-7106, ORNL/TM-2011/298, U.S. NRC, Oak Ridge National Laboratory, (2012).

A.S. Epiney, et al., "New multi-group transport neutronics (PHISICS) capabilities for RELAP5-3D and its application to phase I of the OECD/NEA MHTGR-350 MW benchmark", Proc. of HTR2012, Tokyo, Japan (2012)

M. Goto, et al., "Impact of revised thermal neutron capture cross section of carbon stored in JENDL-4.0 on HTTR criticality calculation ", Journal of Nuclear Science and Technology, Vol. 48, No. 7, pp.965-969 (2011).

C. Hao, F. Li, H. Zhang, "The challenges on uncertainty analysis for pebble bed HTGR", Proc. of PHYSOR 2012, Knoxville, U.S.A., (2012).

A.I. Hawari, V.H. Gillete, "Inelastic thermal neutron scattering cross sections for reactor-grade graphite", Nuclear Data Sheets, Vol. 118, pp. 176-178 (2014). 
D. Ilas, J. Gehin, "HTTR fuel block simulations with SCALE”, Proc. of PHYSOR 2010, Pittsburgh, U.S.A., (2010).

K. Ivanov, et al., "Benchmark for uncertainty analysis in modelling (UAM) for design, operation and safety analysis of LWRs. Volume 1 - specification and supporting data for neutronics cases (Phase I)", NEA/NSC /DOC(2013)7.

P. A. Jansen van Rensburg, M.G. Sage, "Uncertainty analysis for a depressurised loss of forced cooling event of the PBMR reactor", Proc. of ICONE14, Miami, U.S.A., (2006).

J. Kim, G Kim, C. Huh, “Assessment of double heterogeneity treatment capability in SCALE”, Proc. of the $22^{\text {nd }}$ International Conference Nuclear Energy for New Europe, (2013).

J. Leppänen, M. DeHart, "HTGR reactor physics and burnup calculations using the Serpent Monte Carlo code", Trans. Am. Nuc. Soc., Vol. 101, pp. $782-784$ (2009).

J. Leppänen, "Development of a new Monte Carlo reactor physics code", PhD Thesis, Helsinki University of Technology (2007).

L.J. Lommers, B.E. Mays, F. Shahrokhi, "Passive heat removal impact on AREVA HTR design", Nuclear Engineering and Design, 271, pp. 569-577 (2014)

L. Mercatali, et al., "SCALE modeling of selected neutronics test problems within the OECD UAM LWR's benchmark", Science and Technology of Nuclear Installations, Vol. 2013, Article ID 573697 (2013).

National Nuclear Regulator, "Guidance for licensing submissions involving computer software and evaluation models for safety calculations”, LG-1045, South Africa (2006).

OECD/NEA, "Temperature effect on reactivity in VHTRC-1 core”, VHTRC-GCR-EXP-001, CRIT-COEF, NEA/NSC/DOC (2008).

OECD/NEA, "Graphite annular core assemblies with fuel elements containing coated $\mathrm{UO}_{2}$ fuel particles", ASTRA-GCR-EXP-001 (2014).

M. Ouisloumen, R. Sanchez, "A model for neutron scattering off heavy isotopes that accounts for thermal agitation effects”, Nuclear Science and Engineering, Vol. 107, pp. 189-200 (1991).

ORNL/TM-2005/39: "SCALE: A comprehensive modeling and simulation suite for nuclear safety analysis and design", Version 6.1, Oak Ridge National Laboratory, U.S.A., (2011).

B. T. Rearden, et al., "Overview of SCALE 6.2”, Proceedings of ANS NCSD 2013, Wilmington, North Carolina, September 29-October 3, 2013.

F. Reitsma, et. al., "The IAEA CRP on HTGR reactor physics, thermal-hydraulics and depletion uncertainty analysis", Proc. of HTR2012, Tokyo, Japan (2012).

H. Reutler, G.H. Lohnert, "Advantages of going modular in HTR's", Nuclear Engineering and Design, 78, pp. 129-136 (1984).

R.W. Swanson, L.J. Harrison, "The effect of carbon crystal structure on treat reactor physics calculations", CONF-880911-23, DE89 003625, International Reactor Physics Conference, Jackson Hole, U.S.A. (1988).

G. Strydom, "TINTE uncertainty analysis of the maximum fuel temperature during a DLOFC event for the 400 MW Pebble Bed Modular Reactor", Proc. of ICAPP 2004, Pittsburgh, U.S.A., (2004).

B.M. Tyobeka, et.al., "HTGR Reactor physics, thermal-hydraulics and depletion uncertainty analysis: a proposed IAEA coordinated research project", Proc. of M\&C 2011, Rio de Janeiro, Brazil (2011).

U.S. NRC, “10 CFR 50.46: Acceptance criteria for emergency core cooling systems for light-water nuclear power reactors” U.S. Nuclear Regulatory Commission, http://www.nrc.gov/reading-rm/doccollections/cfr/part050/part050-0046.html (2014). 
J.-Y. Wang, et al., "HTTR criticality calculations with SCALE6: Studies of various geometric and unit-cell options in modeling", Proc. of PHYSOR 2012, Knoxville, U.S.A., (2012).

M.-J. Wang, et al., "Criticality calculations of the HTR-10 pebble-bed reactor with SCALE6/CSAS6 and MCNP5", Annals of Nuclear Energy, Vol. 64, pp. 1-7 (2014a).

M.-J. Wang, et al., "Effects of geometry homogenization on the HTR-10 criticality calculations", Nuclear Engineering and Design, 271, pp. 356-360 (2014b).

M. L. Williams, et al., "Development of a statistical sampling method for uncertainty analysis with SCALE", Proc. of PHYSOR 2012, Knoxville, Tennessee, U.S.A., (2012).

M. L. Williams, "Resonance self-shielding methodologies in SCALE 6", Nuclear Technology, Vol. 174, pp. 149168 (2011).

S.-J. Yoon, G. Strydom, "Comparison of homogeneous and heterogeneous CFD fuel models for phase I of the IAEA CRP on HTGR uncertainties benchmark", Proc. of ICAPP 2014, Charlotte, U.S.A., (2014).

J. Žáková, A. Talamo, "Criticality assessment for prismatic high temperature reactors by fuel stochastic Monte Carlo modeling”, Annals of Nuclear Energy, Vol. 35, pp. 856-860 (2008). 
A. Abedi, N. Vasoughi, "Neutronic simulation of a pebble bed reactor considering its double heterogeneous nature”, Nuclear Engineering and Design, Vol. 253, pp. 277-284 (2012).

F. Bostelmann, et al., "Criticality calculations of the Very High Temperature Reactor Critical Assembly benchmark with Serpent and SCALE/KENO-IV”, Annals of Nuclear Energy (in publication).

F. B. Brown, "On the use of shannon entropy of the fission distribution for assessing convergence of Monte Carlo criticality calculations," Proc. of PHYSOR-2006, ANS Topical Meeting on Reactor Physics, Vancouver, Canada, September 10-14, 2006.

M.-H. Chiang, et al., "Evaluation of the HTTR criticality and burnup calculations with continuous-energy and multigroup cross sections", Nuclear Engineering and Design, Vol. 271, pp. 327-331 (2014).

R. J. Ellis, et al., "Generation of a broad-Group HTGR library for use with SCALE", NUREG/CR-7106, ORNL/TM-2011/298, U.S. NRC, Oak Ridge National Laboratory, (2012).

A.S. Epiney, et al., "New multi-group transport neutronics (PHISICS) capabilities for RELAP5-3D and its application to phase I of the OECD/NEA MHTGR-350 MW benchmark", Proc. of HTR2012, Tokyo, Japan (2012).

M. Goto, et al., "Impact of revised thermal neutron capture cross section of carbon stored in JENDL-4.0 on HTTR criticality calculation ", Journal of Nuclear Science and Technology, Vol. 48, No. 7, pp.965-969 (2011).

C. Hao, F. Li, H. Zhang, "The challenges on uncertainty analysis for pebble bed HTGR", Proc. of PHYSOR 2012, Knoxville, U.S.A., (2012).

A.I. Hawari, V.H. Gillete, "Inelastic thermal neutron scattering cross sections for reactor-grade graphite", Nuclear Data Sheets, Vol. 118, pp. 176-178 (2014).

D. Ilas, J. Gehin, "HTTR fuel block simulations with SCALE”, Proc. of PHYSOR 2010, Pittsburgh, U.S.A., (2010).

K. Ivanov, et al., "Benchmark for uncertainty analysis in modelling (UAM) for design, operation and safety analysis of LWRs. Volume 1 - specification and supporting data for neutronics cases (Phase I)", NEA/NSC /DOC(2013)7.

P. A. Jansen van Rensburg, M.G. Sage, "Uncertainty analysis for a depressurised loss of forced cooling event of the PBMR reactor”, Proc. of ICONE14, Miami, U.S.A., (2006).

J. Kim, G Kim, C. Huh, “Assessment of double heterogeneity treatment capability in SCALE”, Proc. of the 22 nd International Conference Nuclear Energy for New Europe, (2013).

J. Leppänen, M. DeHart, "HTGR reactor physics and burnup calculations using the Serpent Monte Carlo code", Trans. Am. Nuc. Soc., Vol. 101, pp. $782-784$ (2009).

J. Leppänen, "Development of a new Monte Carlo reactor physics code”, PhD Thesis, Helsinki University of Technology (2007).

L.J. Lommers, B.E. Mays, F. Shahrokhi, "Passive heat removal impact on AREVA HTR design", Nuclear Engineering and Design, 271, pp. 569-577 (2014)

L. Mercatali, et al., "SCALE modeling of selected neutronics test problems within the OECD UAM LWR's benchmark", Science and Technology of Nuclear Installations, Vol. 2013, Article ID 573697 (2013).

National Nuclear Regulator, "Guidance for licensing submissions involving computer software and evaluation models for safety calculations", LG-1045, South Africa (2006).

OECD/NEA, "Temperature effect on reactivity in VHTRC-1 core”, VHTRC-GCR-EXP-001, CRIT-COEF, NEA/NSC/DOC (2008). 
OECD/NEA, "Graphite annular core assemblies with fuel elements containing coated $\mathrm{UO}_{2}$ fuel particles", ASTRA-GCR-EXP-001 (2014).

M. Ouisloumen, R. Sanchez, "A model for neutron scattering off heavy isotopes that accounts for thermal agitation effects", Nuclear Science and Engineering, Vol. 107, pp. 189-200 (1991).

ORNL/TM-2005/39: "SCALE: A comprehensive modeling and simulation suite for nuclear safety analysis and design”, Version 6.1, Oak Ridge National Laboratory, U.S.A., (2011).

B. T. Rearden, et al., "Overview of SCALE 6.2", Proceedings of ANS NCSD 2013, Wilmington, North Carolina, September 29-October 3, 2013.

F. Reitsma, et. al., "The IAEA CRP on HTGR reactor physics, thermal-hydraulics and depletion uncertainty analysis", Proc. of HTR2012, Tokyo, Japan (2012).

H. Reutler, G.H. Lohnert, "Advantages of going modular in HTR's", Nuclear Engineering and Design, 78, pp. 129-136 (1984).

R.W. Swanson, L.J. Harrison, "The effect of carbon crystal structure on treat reactor physics calculations", CONF-880911-23, DE89 003625, International Reactor Physics Conference, Jackson Hole, U.S.A. (1988).

G. Strydom, "TINTE uncertainty analysis of the maximum fuel temperature during a DLOFC event for the 400 MW Pebble Bed Modular Reactor", Proc. of ICAPP 2004, Pittsburgh, U.S.A., (2004).

B.M. Tyobeka, et.al., "HTGR Reactor physics, thermal-hydraulics and depletion uncertainty analysis: a proposed IAEA coordinated research project", Proc. of M\&C 2011, Rio de Janeiro, Brazil (2011).

U.S. NRC, "10 CFR 50.46: Acceptance criteria for emergency core cooling systems for light-water nuclear power reactors" U.S. Nuclear Regulatory Commission, http://www.nrc.gov/reading-rm/doccollections/cfr/part050/part050-0046.html (2014).

J.-Y. Wang, et al., "HTTR criticality calculations with SCALE6: Studies of various geometric and unit-cell options in modeling", Proc. of PHYSOR 2012, Knoxville, U.S.A., (2012).

M.-J. Wang, et al., "Criticality calculations of the HTR-10 pebble-bed reactor with SCALE6/CSAS6 and MCNP5", Annals of Nuclear Energy, Vol. 64, pp. 1-7 (2014a).

M.-J. Wang, et al., "Effects of geometry homogenization on the HTR-10 criticality calculations", Nuclear Engineering and Design, 271, pp. 356-360 (2014b).

M. L. Williams, et al., "Development of a statistical sampling method for uncertainty analysis with SCALE", Proc. of PHYSOR 2012, Knoxville, Tennessee, U.S.A., (2012).

M. L. Williams, "Resonance self-shielding methodologies in SCALE 6", Nuclear Technology, Vol. 174, pp. 149168 (2011).

S.-J. Yoon, G. Strydom, "Comparison of homogeneous and heterogeneous CFD fuel models for phase I of the IAEA CRP on HTGR uncertainties benchmark", Proc. of ICAPP 2014, Charlotte, U.S.A., (2014).

J. Žáková, A. Talamo, "Criticality assessment for prismatic high temperature reactors by fuel stochastic Monte Carlo modeling”, Annals of Nuclear Energy, Vol. 35, pp. 856-860 (2008). 
Table 1: Serpent and SCALE/KENO-VI multiplication factors for Exercise I-1a

\begin{tabular}{|c|l|l|c|l|l|}
\hline Case & Model & \multicolumn{2}{|l|}{ CZP } & \multicolumn{1}{l|}{ HFP } \\
& & \multicolumn{2}{|c|}{$\begin{array}{l}\Delta \pm \sigma[\mathrm{pcm}] \\
\mathrm{k}_{\infty} \pm \sigma\end{array}$} & $\mathrm{k}_{\infty} \pm \sigma$ & $\begin{array}{l}\Delta \pm \sigma \\
{[\mathrm{pcm}]}\end{array}$ \\
\hline 1 & Serpent: ENDF-B-VII.0 & $1.31698 \pm 0.00019$ & (reference) & $1.18245 \pm 0.00022$ & (reference) \\
2 & Serpent: ENDF-B-VII.1 & $1.31612 \pm 0.00020$ & $-86 \pm 28$ & $1.18124 \pm 0.00021$ & $-121 \pm 29$ \\
3 & KENO-VI CE (6.1.2) & $1.31576 \pm 0.00016$ & $-122 \pm 25$ & $1.18640 \pm 0.00016$ & $395 \pm 25$ \\
4 & KENO-VI CE (6.2b3) & $1.31848 \pm 0.00016$ & $150 \pm 25$ & $1.18383 \pm 0.00015$ & $138 \pm 25$ \\
5 & KENO-VI CE (6.2b3): no DBRC & $1.31885 \pm 0.00016$ & $187 \pm 25$ & $1.18994 \pm 0.00018$ & $749 \pm 27$ \\
6 & KENO-VI CE (6.2b4): ENDF-B-VII.0 & $1.31859 \pm 0.00015$ & $161 \pm 25$ & $1.18375 \pm 0.00016$ & $130 \pm 25$ \\
7 & KENO-VI CE (6.2b4): ENDF-B-VII.1 & $1.31674 \pm 0.00016$ & $62 \pm 26^{\text {a }}$ & $1.18285 \pm 0.00015$ & $161 \pm 25^{\text {a }}$ \\
8 & KENO-VI 238 MG (6.1.2) & $1.30897 \pm 0.00014$ & $-801 \pm 24$ & $1.18188 \pm 0.00014$ & $-57 \pm 24$ \\
9 & KENO-VI 238 MG (6.2b3) & $1.30941 \pm 0.00013$ & $-757 \pm 24$ & $1.18158 \pm 0.00013$ & $-87 \pm 24$ \\
10 & KENO-VI 252 MG (6.2b3) & $1.30912 \pm 0.00015$ & $-786 \pm 25$ & $1.18295 \pm 0.00016$ & $50 \pm 25$ \\
\hline
\end{tabular}

Table 2: Serpent and SCALE/KENO-VI multiplication factors for Exercise I-1b

\begin{tabular}{|c|c|c|c|c|c|}
\hline \multirow[b]{2}{*}{ שֶ } & \multirow[b]{2}{*}{ Model } & \multicolumn{2}{|l|}{$\mathbf{C Z P}$} & \multicolumn{2}{|c|}{ HFP } \\
\hline & & $\mathrm{k}_{\infty} \pm \sigma$ & $\begin{array}{l}\Delta \pm \sigma \\
{[\mathrm{pcm}]}\end{array}$ & $\mathrm{k}_{\infty} \pm \sigma$ & $\begin{array}{c}\Delta \pm \sigma \\
[\mathrm{pcm}])\end{array}$ \\
\hline 1 & Serpent - random: ENDF-B-VII.0 & $1.37060 \pm 0.00021$ & (ref.) & $1.24461 \pm 0.00023$ & (ref.) \\
\hline 2 & Serpent - random: ENDF-B-VII.1 & $1.36899 \pm 0.00021$ & $-161 \pm 30$ & $1.24335 \pm 0.00024$ & $-126 \pm 32$ \\
\hline 3 & Serpent - reg. lattice: ENDF-B-VII.0 & $1.37642 \pm 0.00021$ & $582 \pm 30$ & $1.25071 \pm 0.00024$ & $610 \pm 32$ \\
\hline 4 & KENO-VI CE - reg. lattice (6.1.2) & $1.37276 \pm 0.00015$ & $\begin{array}{l}216 \pm 26 \\
-366 \pm 26^{\text {a }}\end{array}$ & $1.25264 \pm 0.00018$ & $\begin{array}{l}803 \pm 280 \\
193 \pm 30^{\text {a }}\end{array}$ \\
\hline 5 & KENO-VI CE - reg. lattice (6.2b3) & $1.37480 \pm 0.00015$ & $\begin{array}{l}420 \pm 20 \\
-162 \pm 22^{a}\end{array}$ & $1.25164 \pm 0.00016$ & $\begin{aligned} 703 & \pm 27 \\
93 & \pm 25^{a}\end{aligned}$ \\
\hline 6 & $\begin{array}{l}\text { KENO-VI CE - reg. lattice (6.2b3): no } \\
\text { DBRC }\end{array}$ & $1.37505 \pm 0.00015$ & $\begin{aligned} 445 & \pm 26 \\
25 & \pm 26^{b}\end{aligned}$ & $1.25811 \pm 0.00015$ & $\begin{array}{l}1350 \pm 26 \\
647 \pm 22^{b}\end{array}$ \\
\hline 7 & $\begin{array}{l}\text { KENO-VI CE - reg. lattice }(6.2 \mathrm{~b} 4) \text { : } \\
\text { ENDF-B-VII.0 }\end{array}$ & $1.37731 \pm 0.00015$ & $\begin{aligned} 671 & \pm 26 \\
89 & \pm 22 \text { a }\end{aligned}$ & $1.25158 \pm 0.00017$ & $\begin{array}{r}697 \pm 28 \\
87 \pm 23^{\text {a }}\end{array}$ \\
\hline 8 & $\begin{array}{l}\text { KENO-VI CE - reg. lattice (6.2b4): } \\
\text { ENDF-B-VII.1 }\end{array}$ & $1.37599 \pm 0.00015$ & $700 \pm 26^{c}$ & $1.25044 \pm 0.00015$ & $709 \pm 26^{c}$ \\
\hline 9 & KENO-VI 238 MG/DOUBLEHET (6.1.2) & $1.36162 \pm 0.00015$ & $-898 \pm 26$ & $1.24202 \pm 0.00013$ & $-259 \pm 25$ \\
\hline 10 & $\begin{array}{l}\text { KENO-VI } 238 \text { MG/DOUBLEHET } \\
(6.2 \mathrm{~b} 3)\end{array}$ & $1.36367 \pm 0.00013$ & $-693 \pm 25$ & $1.24350 \pm 0.00014$ & $-111 \pm 26$ \\
\hline 11 & $\begin{array}{l}\text { KENO-VI } 252 \text { MG/DOUBLEHET } \\
(6.2 \mathrm{~b} 3)\end{array}$ & $1.36361 \pm 0.00013$ & $-699 \pm 25$ & $1.24475 \pm 0.00015$ & $14 \pm 26$ \\
\hline
\end{tabular}

a. Difference with respect to Serpent lattice (ENDF-B-VII.O) result. b. Difference with respect to KENO-VI CE reg. lattice (6.2b3) result. c. Difference with respect to Serpent random (ENDF-B-VII.1) result.

Table 3: Comparison between Exercise I-1a and I-1b

\begin{tabular}{|l|cc|cc|}
\hline \multicolumn{1}{|c|}{ Model } & \multicolumn{2}{|c|}{ CZP } & \multicolumn{2}{c|}{ HFP } \\
& $\mathrm{k}_{\infty} \pm \sigma$ & $\Delta \pm \sigma[\mathrm{pcm}]$ & $\mathrm{k}_{\infty} \pm \sigma$ & $\Delta \pm \sigma[\mathrm{pcm}]$ \\
\hline $\begin{array}{l}\text { Serpent - random (ENDF-B-VII.0) } \\
\text { heterogeneous }\end{array}$ & $1.37060 \pm 0.00021$ & (reference) & $1.24461 \pm 0.00023$ & (reference) \\
Serpent (ENDF-B-VII.0): homogeneous & $1.31698 \pm 0.00019$ & $-5362 \pm 29$ & $1.18245 \pm 0.00022$ & $-6216 \pm 32$ \\
KENO-VI CE (6.1.2): homogeneous & $1.31576 \pm 0.00016$ & $-5484 \pm 27$ & $1.18640 \pm 0.00016$ & $-5821 \pm 29$ \\
KENO-VI 238 MG (6.1.2): homogeneous & $1.30897 \pm 0.00014$ & $-6163 \pm 26$ & $1.18188 \pm 0.00014$ & $-6273 \pm 27$ \\
\hline
\end{tabular}


Table 4. Comparison of three Exercise I-1b variants (Serpent random particle distribution).

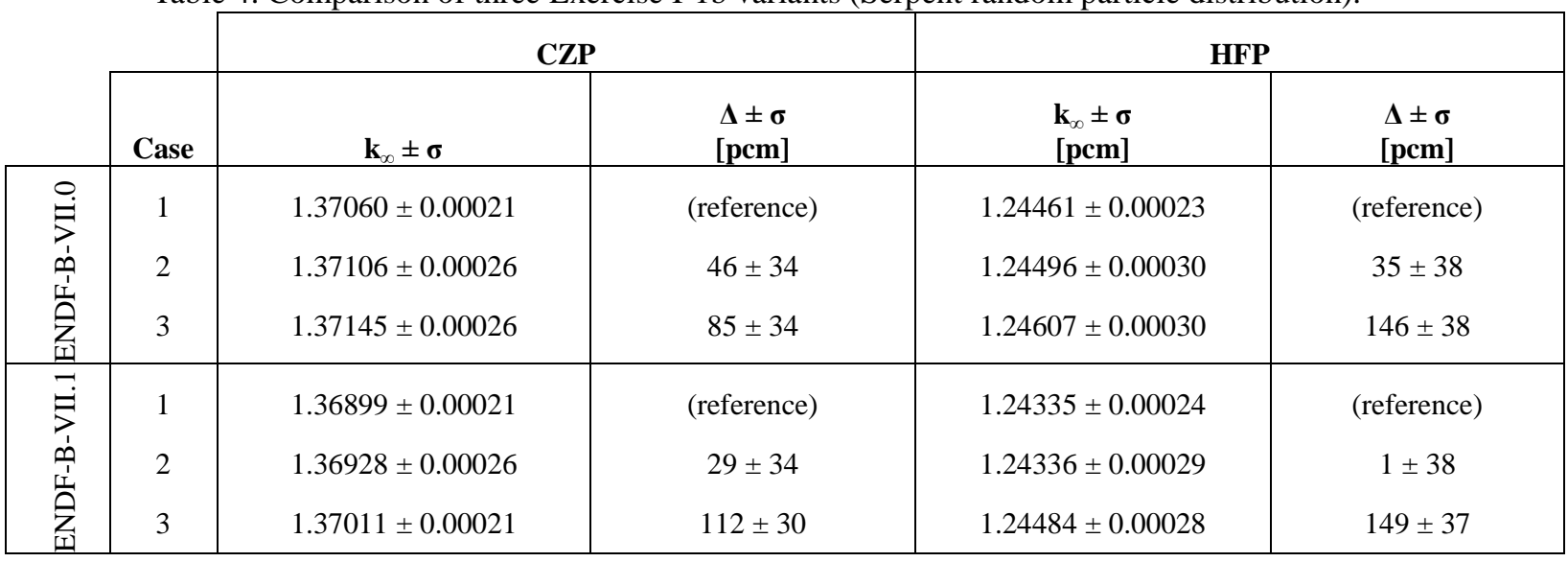

Table 5: Top 5 nuclide reaction covariance contributors to $\mathrm{k}_{\infty}$ uncertainty - Ex. I-1a HFP

\begin{tabular}{|l|l|c|}
\hline Rank & Nuclide reaction pair & $\begin{array}{l}\text { Uncertainty contribution due } \\
\text { to this matrix }(\% \mathbf{~} \mathbf{k} / \mathbf{k})\end{array}$ \\
\hline 1 & ${ }^{238} \mathrm{U}(\mathrm{n}, \gamma) /{ }^{238} \mathrm{U}(\mathrm{n}, \gamma)$ & 0.398 \\
2 & ${ }^{235} \mathrm{U}(\bar{v}) /{ }^{235} \mathrm{U}(\bar{v})$ & 0.261 \\
3 & ${ }^{235} \mathrm{U}(\mathrm{n}, \gamma) /{ }^{235} \mathrm{U}(\mathrm{n}, \gamma)$ & 0.256 \\
4 & $\mathrm{C}$-graphite elastic / C-graphite elastic & 0.128 \\
5 & $\mathrm{U}-238$ elastic / U-238 elastic & 0.124 \\
\hline $\mathrm{k}_{\infty}$ standard deviation due to nuclide reaction \\
covariance data \\
\hline k \\
$\begin{array}{l}\text { Carlo sampling (from KENO-VI forward } \\
\text { solution) }\end{array}$ \\
\hline \multicolumn{2}{|l|}{ Total $\mathrm{k}_{\infty}$ standard deviation } \\
\hline
\end{tabular}

